\title{
Die Verwirklichung des europäischen Binnenmarkts im Transport- und Verkehrsrecht
}

\author{
Christoph Perathoner
}

\section{Bedeutung der Verkehrspolitik für die Realisierung des Binnenmarktziels}

$\mathrm{Zu}$ den unabdingbaren Voraussetzungen einer jeden modernen Industriegesellschaft gehören die funktionierende Mobilität der Menschen und ein effizienter Transport der Waren. ${ }^{1}$

\footnotetext{
${ }^{1}$ Instruktiv E. Brandt, Verkehrspolitik und transeuropäische Netze, in: M. Röttinger/C. Weyringer (Hrsg.), Handbuch der europäischen Integration, Manz, Wien, 2. Aufl. 1996, S. 917 (918 f.); vgl. auch R. Bieber/F. Maiani, Europäisches Verkehrsrecht. Die Rechtspraxis sämtlicher Verkehrsträger, Nomos, Baden-Baden, 2015, S. 27.
}

C. Perathoner $(\square)$

Rechtsanwaltssozietät Christoph Perathoner \& Partner, Bozen, Italien

E-Mail: christoph.perathoner@ perathoner-partner.com

S. Laimer, C. Perathoner (Hrsg.), Mobilitäts- und Transportrecht in Europa,

Bibliothek des Wirtschaftsrechts 2,

https://doi.org/10.1007/978-3-662-63635-0_1 
Die Verkehrspolitik nimmt deshalb heute - aber es war nicht immer so $^{2}-$ in den Aufgabenbereichen der Europäischen Union eine herausragende Stellung ein. ${ }^{3}$ Dies zeigt sich bereits auf primärrechtlicher Ebene in Art. 3 EUV, der die Zielvorgaben der Union festschreibt. Im zweiten Absatz dieser Vorschrift wird auf die Schaffung eines Raums der Freiheit, der Sicherheit und des Rechts ohne Binnengrenzen verwiesen, wobei hier insbesondere die Abschaffung der Personenkontrollen an den Binnengrenzen ${ }^{4}$ beziehungsweise die Grundfreiheit des freien Personenverkehrs ${ }^{5}$ eine essenzielle Rolle spielen. ${ }^{6}$

Die zentrale Bedeutung der Verkehrspolitik in Bezug auf die Wirtschaft wird in Art. 3 Abs. 3 EUV verdeutlicht. Die Errichtung eines Binnenmarkts ${ }^{7}$ als wesentliche

\footnotetext{
${ }^{2}$ In den ersten Jahrzehnten nach der Gründung der Europäischen Wirtschaftsgemeinschaft waren die führenden Mitgliedstaaten sehr zurückhaltend was die Begründung einer gemeinsamen Verkehrs- und Transportpolitik angeht. In vielen Staaten wurde dieser Bereich von politisch einflussreichen Staatsunternehmen, wie der Société Nationale des Chemins de fer Français, der Deutschen Bundesbahn, oder den Ferrovie dello Stato Italiane kontrolliert, die sich schwer für eine Harmonisierung oder gar Liberalisierung des Sektors begeistern konnten. So kam es, dass das Europäische Parlament in den achtziger Jahren, nach politischen Debatten in den entsprechenden Gremien, eine Untätigkeitsklage auf dem Gebiet der Verkehrspolitik gegen den Rat der Europäischen Gemeinschaft beim Gerichtshof einbrachte. Dieser gab dem Europäischen Parlament Recht und forderte ein entsprechendes Handeln der Gemeinschaftsorgane ein; siehe dazu EuGH, Urteil vom 22. Mai 1985, Rs. 13/83, Europäisches Parlament gegen Rat der Europäischen Gemeinschaften, in: Sammlung der Rechtsprechung, 1985, S. 1513 ff., ECLI:EU:C:1985:220. Hinsichtlich der Urteilsanmerkungen, siehe M.L. Tufano, Sui ritardi del Consiglio in materia di politica comunitaria dei trasporti, in: Il Foro italiano, 1986, IV, S. 253 ff.; Ph. Fennel, The Transport Policy Case, in: European Law Review, 1985, S. 264 ff.; J. Erdmenger, Die EG-Verkehrspolitik vor Gericht - das EuGH-Urteil Rs. 13/83 vom 22/05/1985 und seine Folgen, in: Europarecht, 1985, S. 375 ff.; M. Arpio Santacruz, El Parlamento frente al Consejo: la sentencia del Tribunal de Justicia en materia de transportes, in: Revista de Instituciones Europeas, 1985, S. 789 ff. Zu den Anfängen der Verkehrspolitik der EU E. Müller-Hermann, Die Grundlagen der gemeinsamen Verkehrspolitik in der Europäischen Wirtschaftsgemeinschaft, Kirschbaum-Verlag, Bad Godesberg, 1963; R. Wijffels/W. Stabenow/L. van Huffel (Hrsg.), Gemeinsamer Markt und Verkehr, Sonderausgabe Antwerpen, Europäisches Transportrecht, 1969; siehe auch A. Epiney/J. Heuck/Y. Schleiss, Verkehrsrecht, in: M.A. Dauses/M. Ludwigs (Hrsg.), Handbuch des EU-Wirtschaftsrecht, C.H. Beck, München, 33, EL 2013, L, Rn. 226 ff.

${ }^{3}$ Allgemein R. Bieber/F. Maiani, Europäisches Verkehrsrecht. Die Rechtspraxis sämtlicher Verkehrsträger, Nomos, Baden-Baden, 2015, S. 31 ff.; zur Integrationswirkung von Verkehrsprojekten für die Europäische Union vgl. $H$. Witte, Transeuropäische Verkehrsnetze: Integrationswirkungen von Verkehrssystemen, makroökonomische und regionalpolitische Implikationen der prioritären Verkehrsprojekte, in: W. Zippel (Hrsg.), Transeuropäische Netze, Nomos, Baden-Baden, 1996, S. 63 (69 f.).

${ }^{4}$ Vgl. Art. 67 Abs. 2 sowie Art. 77 Abs. 1 lit. a) AEUV.

${ }^{5}$ Vgl. Art. 21 AEUV; Titel IV und V AEUV; Art. 45 Charta der Grundrechte der Europäischen Union.

${ }^{6}$ Allgemein zum Thema N. Ehlotzky, Grundfreiheiten im Spannungsfeld von Verkehr und Nachhaltigkeit. Eine Analyse anhand des Verkehrsprotokolls der Alpenkonvention, Nomos, Baden-Baden, 2014.

${ }^{7}$ Zum Ziel des Binnenmarkts vgl. E. Grabitz/A. von Bogdandy, Vom gemeinsamen Markt zum Binnenmarkt, in: JuS, 1990, S. 170 ff.; im Kontext der Verkehrspolitik etwa N. Ehlotzky, Grundfreiheiten im Spannungsfeld von Verkehr und Nachhaltigkeit. Eine Analyse anhand des Verkehrsprotokolls der Alpenkonvention, Nomos, Baden-Baden, 2014, S. 74 ff.
} 
Daueraufgabe ${ }^{8}$ der Union ist ohne freien Verkehr innerhalb der Binnengrenzen nicht denkbar. ${ }^{9}$ Die europäische Integration implizierte so von Anfang an eine Internationalisierung, aber vor allem auch eine Intensivierung und Dynamisierung des Austausches der Personen und Güter in Europa. Dies ist wiederum nur durch einen effizienten Transport umsetzbar. ${ }^{10}$

Im Lichte dieser Zielvorgabe, steht der Binnenraum für die Schaffung eines Wirtschaftsraums ohne innere Grenzen für den freien Verkehr von Waren, Personen, Dienstleistungen und Kapital. ${ }^{11}$ Eine Legaldefinition findet sich in Art. 26 Abs. 2 AEUV, wonach dieser ,ein Raum ohne Binnengrenzen [ist], in dem der freie Verkehr von Waren, Personen, Dienstleistungen und Kapital gemäß den Bestimmungen der Verträge gewährleistet ist. "12 Diese Begriffsbestimmung ist allerdings keine abschließende, weil nicht ausdrücklich erwähnte Positionen - wie die sogenannte Annexfreiheit des Zahlungsverkehrs ${ }^{13}$ - gleichsam in das Binnenmarktziel einfließen und durchaus eine prägende Rolle in der Praxis spielen. ${ }^{14}$ Daneben werden noch weitere Aspekte erfasst, etwa das Verbot von Ein- und Ausführzöllen zwischen Mitgliedstaaten, ${ }^{15}$ die Bedeutung des Wettbewerbsrechts ${ }^{16}$ und die inhaltlich nahestehenden Politikschwerpunkte, wie die gemeinsame Handelspolitik. ${ }^{17}$ Um das Konzept kurz auf den Punkt zu bringen, kann die Formel für den gemeinsamen Markt bedient werden: Freiheit nach innen schaffen, Einheit nach außen vermitteln. ${ }^{18}$

\footnotetext{
${ }^{8}$ So J. P. Terhechte, in: E. Grabitz/M. Hilf/N. Nettesheim (Hrsg.), Das Recht der Europäischen Union, 60. Ergänzungslieferung - Stand Oktober 2016, C.H. Beck, München, Art. 3 EUV, Rn. 38 m.w.N.

${ }^{9}$ Allgemein zum Thema F. Kainer/J. Persch, Der Verkehr im Binnenmarktrecht: Sonderfall oder Dienstleistung? Anstöße für eine Reform der Art. 90 ff. AEUV, in: EuR, 2018, 1, S. 33 ff.

${ }^{10}$ Vgl. J. P. Terhechte, in E. Grabitz/M. Hilf/N. Nettesheim (Hrsg.), Das Recht der Europäischen Union, 60. Ergänzungslieferung - Stand Oktober 2016, C.H. Beck, München, Art. 3 EUV, Rn. 38 m.w.N.

${ }^{11}$ Instruktiv R. Bieber/F. Maiani, Europäisches Verkehrsrecht. Die Rechtspraxis sämtlicher Verkehrsträger, Nomos, Baden-Baden, 2015, S. 71 ff.; A. Epiney, in: R. Bieber/A. Epiney/M. Haag/M. Kotzur (Hrsg.), Die Europäische Union. Europarecht und Politik, Nomos, Baden-Baden, 12. Aufl. 2016, $\S 11$, Rn. 1 ff.

${ }^{12}$ Zum Begriff des Binnenmarkts vgl. N. Reich, Binnenmarkt als Rechtsbegriff, in: EuZW, 1991, S. $203 \mathrm{ff}$.
}

${ }^{13}$ Die in Art. 63, Abs. 2 AEUV garantierte Freiheit des Zahlungsverkehrs ist eine wesentliche Grundvoraussetzung, damit - vor allem in der Praxis - die EU-Grundfreiheiten überhaupt erst funktionieren und abgesichert werden können. Es handelt sich bei der Freiheit des Zahlungsverkehrs somit um keine ,echte“ Grundfreiheit, sondern vielmehr um einen Annex zu den vier Grundfreiheiten.

${ }^{14}$ J. P. Terhechte, in: E. Grabitz/M. Hilf/M. Nettesheim (Hrsg.), Das Recht der Europäischen Union, 60. Ergänzungslieferung - Stand Oktober 2016, C.H. Beck, München, Art. 3 EUV, Rn. 39.

${ }^{15}$ Vgl. Art. 28 Abs. 1 AEUV.

${ }^{16} \mathrm{Vgl}$. Art. $101 \mathrm{ff}$. AEUV.

${ }^{17} \mathrm{Vgl}$. Art. 206 f. AEUV.

${ }^{18}$ Vgl. etwa A. Hatje, in: H. von der Groeben/J. Schwarze/A. Hatje (Hrsg.), Europäisches Unionsrecht: Vertrag über die Europäische Union, Vertrag über die Arbeitsweise der Europäischen Union, 
Bei der Verwirklichung des Binnenmarkts weist der Verkehr eine doppelte Funktion für die europäische Integration auf. ${ }^{19}$ Einerseits bildet er dessen Instrument, zumal ein freier Verkehr von Waren und Personen ohne die entsprechende Güter- und Personenbeförderung nicht denkbar wäre. Andererseits ist er auch Gegenstand der europäischen Integration, da die im Verkehr behängenden 11 Millionen Arbeitsplätze ${ }^{20}$ etwa $5 \%$ des gesamten Bruttoinlandsprodukts der Union ausmachen. ${ }^{21}$ Außerdem entfällt ein hoher Anteil der öffentlichen Investitionen auf die Verkehrsinfrastruktur. So flossen im Zeitraum 2007-2020 Finanzmittel in Höhe von rund 193 Milliarden Euro in den Verkehrssektor. ${ }^{22}$ Die Herstellung vieler Güter des alltäglichen Gebrauchs sowie komplexer Maschinen konzentriert sich nicht mehr bloß auf eine einzige Produktionsstätte. Rohstoffe, Halbfabrikate und Montagetätigkeiten entstammen oder erfolgen in unterschiedlichen Ländern, wodurch der Verkehr heute zur notwendigen Voraussetzung der industriellen Produktion wird. ${ }^{23}$

Zusammenfassend lässt sich also einleitend sagen: Mobilität und Verkehr sind unabdingbar für das Funktionieren einer modernen Gesellschaft ${ }^{24}$ und bilden zusammen mit anderen Faktoren die Grundlage der europäischen Integration. Zudem bildet der flächendeckende Ausbau nachhaltiger Verkehrsnetze eine notwendige Voraussetzung für die Verwirklichung und das Funktionieren des europäischen Binnenmarktes. ${ }^{25}$

Charta der Grundrechte der Europäischen Union, Bd. 1, Nomos, Baden-Baden, 7. Aufl. 2015, Art. 26 AEUV, Rn. 8.

${ }^{19}$ So C.D. Classen, in T. Oppermann/C.D. Classen/M. Nettesheim, Europarecht, C.H. Beck, München, 8. Aufl. 2018, § 26, Rn. 1.

${ }^{20}$ Dies entspricht 5,2\% aller Arbeitsplätze in der EU.

${ }^{21}$ Siehe dazu Europäischer Rechnungshof (Hrsg.), Hin zu einem optimierten Verkehrssektor in der EU: Welche Herausforderungen gilt es zu bewältigen? Landscape-Analyse, Luxemburg, 2018, S. 4, abrufbar unter https://www.eca.europa.eu/Lists/ECADocuments/LR_TRANSPORT/LR_ TRANSPORT_DE.pdf (21.08.2021). Siehe auch Europäische Kommission (Hrsg.), Delivering TEN-T - Facts and Figures, September 2017, Brüssel, 2017, S. 5, online: https://ec.europa.eu/ transport/sites/default/files/delivering_ten_t.pdf (21.08.2021).

${ }^{22} \mathrm{Vgl}$. dazu Europäischer Rechnungshof (Hrsg.), Hin zu einem optimierten Verkehrssektor in der EU: Welche Herausforderungen gilt es zu bewältigen? Landscape-Analyse, Luxemburg, 2018, S. $13 \mathrm{f}$.

${ }^{23}$ Vgl. A. Antonini, Corso di diritto dei trasporti, Giuffrè Editore, Milano, 3. Aufl. 2015, S. 4.

${ }^{24} \mathrm{Zu}$ diesem Thema: E. Brandt, Verkehrspolitik und transeuropäische Netze, in: M. Röttinger/C. Weyringer (Hrsg.), Handbuch der europäischen Integration, Manz, Wien, 2. Aufl. 1996, S. 917 (918 f.); siehe auch R. Bieber/F. Maiani, Europäisches Verkehrsrecht. Die Rechtspraxis sämtlicher Verkehrsträger, Nomos, Baden-Baden, 2015, S. 27.

${ }^{25}$ Siehe Europäischer Rechnungshof (Hrsg.), Hin zu einem optimierten Verkehrssektor in der EU: Welche Herausforderungen gilt es zu bewältigen? Landscape-Analyse, Luxemburg, 2018, S. 4. 


\section{EU-Verkehrspolitik: Primärrechtliche Grundlagen}

Die Realisierung der Ziele der Gemeinsamen Verkehrspolitik (GVP) der Union wird in den Art. 90 bis 100 AEUV bzw. von Titel VI des dritten Teils des AEUV geregelt. ${ }^{26}$ Die Bestimmungen erfassen alle fünf Hauptverkehrsarten: (a) Schienenverkehr, (b) Straßenverkehr, (c) Binnenschifffahrt, (d) Schifffahrt und (e) Luftverkehr. Die gegenwärtige Normierung in Titel VI bildet jedoch verschiedentlich Gegenstand von Kritik. Dabei wird argumentiert, dass die darin enthaltenen Regelungen in ihrer Gesamtheit unzureichend, unstrukturiert und ohne klaren Leitfaden seien $^{27}$ bzw. die Definition der gesetzten Ziele jene Bestimmtheit vermissen ließe, die für eine der wichtigsten Politiken der Union notwendig oder zumindest angebracht wäre. ${ }^{28}$

Für einen allgemeinen Überblick über die Bestimmungen des AEUV ist es wichtig, insbesondere zwei Kategorien von Normen zu unterscheiden: einerseits Bestimmungen allgemeiner Tragweite, welche die Transporttätigkeit als solche und nicht lediglich ihren Aspekt als Kostenfaktor für Güter betreffen (Art. 90 bis 94 AEUV); andererseits spezifische Bestimmungen zur Beförderung von Gütern im Landverkehr, die dazu bestimmt sind, etwaige Hindernisse zu beseitigen, die aus dieser Verkehrsart für den allgemeinen Binnenmarkt entstehen könnten (Art. 95 bis 97 AEUV). ${ }^{29}$

Die Bestimmungen der Art. 94, 97 und auch 98 AEUV haben dabei heute keine praktische Relevanz mehr und sind als obsolet anzusehen.

Doch was wird von der gemeinsamen Verkehrspolitik erfasst? Diesbezüglich bleibt Art. 90 AEUV insgesamt „,merkwürdig unbestimmt“ ${ }^{30}$ während inhaltliche Bezugspunkte in Art. 100 AEUV näher konkretisiert werden. Letztere Vorschrift erstreckt die geregelte EU-Verkehrspolitik auf den gewerblichen und individuellen Eisenbahn-, Straßen- und Binnenschiffsverkehr, einschließlich des sogenannten kombinierten (Land-)Verkehrs. Außerdem können das Europäische Parlament und der Rat nach Art. 100 Abs. 2 AEUV im Rahmen des ordentlichen Gesetzgebungsverfahrens ${ }^{31}$ Vorschriften in Bezug auf die Seeschifffahrt ${ }^{34}$ und die Luftfahrt ${ }^{35}$ erlassen, nachdem der Europäische Wirtschafts- und Sozialausschuss (EWSA) ${ }^{32}$

\footnotetext{
${ }^{26}$ Einführend bei $M$. Krajewski, Grundstrukturen des Rechts öffentlicher Dienstleistungen, Springer, Berlin Heidelberg, 2011, S. 230 ff.; siehe auch Vgl. C.D. Classen, in T. Oppermann/ C.D. Classen/M. Nettesheim, Europarecht, C.H. Beck, München, 8. Aufl. 2018, § 26, Rn. 4 f.

${ }^{27}$ Siehe $R$. Adam/A. Tizzano, Manuale di diritto dell'Unione Europea, G. Giappichelli Editore, Torino, 2. Aufl. 2017, S. 586 f.

${ }^{28}$ Siehe R. Bieber/F. Maiani, Europäisches Verkehrsrecht. Die Rechtspraxis sämtlicher Verkehrsträger, Nomos, Baden-Baden, 2015, S. 43.

${ }^{29} \mathrm{Vgl}$. ebenda.

${ }^{30} \mathrm{Vgl}$. ebenda.

${ }^{31}$ Siehe dazu Art. 289 und 294 AEUV.

${ }^{32}$ Siehe https://www.eesc.europa.eu/de (21.08.2021).
} 
sowie der Europäische Ausschuss der Regionen (AdR) $)^{33}$ konsultiert wurden. ${ }^{34}$ Damit sind das Post- und Fernmeldewesen, Seilbahnen, aber auch die Raumfahrt ${ }^{35}$ nicht von diesem Titel erfasst. ${ }^{36}$

Aus Art. 58 AEUV lässt sich zudem ableiten, dass die gemeinsame Verkehrspolitik der Union nicht nur (im engeren Sinne) die Beförderung von Personen und Waren von einem Ort zum anderen erfasst, sondern auch alle anderen Dienstleistungen, die naturgemäß mit Verkehr und Transport verbunden sind. ${ }^{37}$

Die Transeuropäischen Netze (TEN), die für den Verkehrs-, Telekommunikations- und Energiesektor von zentraler Bedeutung sind, werden im Titel XVI des dritten Teils des AEUV (Art. 170-172), geregelt.

\subsection{Kompetenzaufteilung zwischen Union und Mitgliedstaaten}

Die gemeinsame Verkehrspolitik zählt zu den geteilten Zuständigkeiten der Europäischen Union. ${ }^{38}$ Demnach ist die Union im Verkehrssektor zum Erlass von Gesetzgebungsakten berechtigt. Wird sie hier aber nicht tätig, liegt die Zuständigkeit bei den einzelnen Mitgliedstaaten. Präziser ausgedrückt, können die Mitgliedsstaaten nur dann in Bereichen der geteilten Zuständigkeiten gesetzgeberisch tätig werden, wenn die Union ihre Vorrechte noch nicht wahrgenommen hat, also ihre Kompetenz nicht ausgeübt hat. Liegt eine Kompetenzausübung seitens der Union vor, haben die Mitgliedstaaten die Möglichkeit, erneut ihre Kompetenz auszuüben. Dies jedoch nur in dem Maße, in dem die Union selbst ihre Kompetenz nicht ausgeübt hat. ${ }^{39}$ Dem nicht entgegenstehend, findet auch der Subsidiaritätsgrundsatz ${ }^{40}$ Anwendung, welcher im Jahre 1992 mit dem Vertrag von Maastricht ${ }^{41}$ eingeführt worden war und vorsieht, dass die Union in allen Bereichen, in denen sie keine ausschließliche

\footnotetext{
${ }^{33}$ Siehe https://cor.europa.eu/de (21.08.2021).

${ }^{34}$ Die gesonderte Aufzählung von See- und Luftverkehr hat nach R. Bieber, in: R. Bieber/A. Epiney/M. Haag/M. Kotzur (Hrsg.), Die Europäische Union. Europarecht und Politik, Nomos, Baden-Baden, 12. Aufl. 2016, § 24 Rn. 4, historische Gründe; im Übrigen sind die Art. 92 bis 99 AEUV für diese beiden Verkehrsträger nicht anwendbar.

${ }^{35}$ Gleichwohl ist die Raumfahrt aber seit dem Vertrag von Lissabon im Rahmen der Forschungspolitik in Art. 189 AEUV erfasst.

${ }^{36}$ So R. Bieber, in: R. Bieber/A. Epiney/M. Haag/M. Kotzur (Hrsg.), Die Europäische Union. Europarecht und Politik, Nomos, Baden-Baden, 12. Aufl. 2016, § 24 Rn. 6.

${ }^{37}$ Vgl. C.D. Classen, in: T. Oppermann/C.D. Classen/M. Nettesheim, Europarecht, C.H. Beck, München, 8. Aufl. 2018, § 26 Rn. 4.

${ }^{38}$ Vgl. Art. 4 Abs. 2 lit. g) und h) AEUV.

${ }^{39}$ Siehe dazu Art. 2, Abs. 2 AEUV; siehe auch EuGH, Urteil vom 13. Februar 1969, Rs. 14/68, Walt Wilhelm et al. gegen Bundeskartellamt, in: Sammlung der Rechtsprechung, 1969, S. 1 ff., ECLI:EU:C:1969:4.

${ }^{40} \mathrm{Vgl}$. Art. 5 AEUV.

${ }^{41}$ Siehe Vertrag über die Europäische Union, in: Abl., 29. Juli 1992, C 191, S. 1 ff.; ELI: http://data. europa.eu/eli/treaty/teu/sign (21.08.2021).
} 
Kompetenz besitzt, nur dann eingreift, wenn die angestrebten Ziele von den Mitgliedstaaten nicht im ausreichendem Maße erfüllt werden können. ${ }^{42}$ Daraus kann geschlossen werden, dass neben der europäischen Regelung weiterhin eine nicht unbeachtliche nationale Gesetzgebungskompetenz vorliegt, welche aber stets unter Achtung des Grundsatzes der loyalen Zusammenarbeit zwischen den Mitgliedstaaten und der Union ausgeübt werden muss. ${ }^{43}$

Die zentrale verfahrensrechtliche Vorschrift zur Gestaltung der Verkehrspolitik findet sich in Art. 91 Abs. 1 AEUV. ${ }^{44}$ Diese Norm sieht vor, dass das Europäische Parlament und der Rat, nach entsprechender Anhörung des Europäischen Wirtschafts- und Sozialausschusses sowie des Europäischen Ausschusses der Regionen, im Rahmen des ordentlichen Gesetzgebungsverfahrens (a) gemeinsame Regeln für den grenzüberschreitenden und internationalen Verkehr, (b) die Bedingungen für die Zulassung von Verkehrsunternehmen innerhalb eines Mitgliedstaates, in dem sie nicht ansässig sind sowie (c) allfällige Maßnahmen zur Verbesserung der Verkehrssicherheit erlassen. ${ }^{45}$ Allerdings kann die Union über die Auffangklausel in Art. 91 Abs. 1 lit. d AEUV (,,alle sonstigen zweckdienlichen Vorschriften") in umfassender Weise die Verkehrspolitik gestalten. ${ }^{46}$

Gleichzeitig beinhaltet Art. 91 Abs. 1 AEUV das Gebot der Berücksichtigung der Besonderheiten des Verkehrs. Mit Blick auf regionale Besonderheiten normiert der zweite Absatz der Vorschrift ausdrücklich die Beachtung des Lebensstandards und der Beschäftigungslage in bestimmten Regionen, aber auch den Betrieb der Verkehrseinrichtungen selbst.

Für die Mitgliedstaaten hingegen gilt nach Art. 92 AEUV eine sogenannte Stillhalteverpflichtung. Demnach dürfen die Mitgliedstaaten ihre Verkehrsunternehmen bis zum Erlass des einschlägigen europäischen Sekundärrechts nicht zusätzlich begünstigen. Daneben gilt ein Diskriminierungsverbot für Beförderungsbedingungen,

\footnotetext{
${ }^{42}$ Siehe Art. 5 Abs. 3 EUV; Protokoll (Nr. 2) über die Anwendung der Grundsätze der Subsidiarität und der Verhältnismäßigkeit, in: Abl., 9. Mai 2008, C 115, S. 206 ff.

${ }^{43}$ Siehe Art. 2 Abs. 3 EUV.

${ }^{44}$ Ausführlich R. Bieber/F. Maiani, Europäisches Verkehrsrecht. Die Rechtspraxis sämtlicher Verkehrsträger, Nomos, Baden-Baden, 2015, S. 53 ff.

${ }^{45}$ Zur Situation ante Lissabon vgl. M. Krajewski, Grundstrukturen des Rechts öffentlicher Dienstleistungen, Springer, Berlin-Heidelberg, 2011, S. 232 ff. m.w.N.

${ }^{46}$ So R. Bieber, Verkehrspolitik und Transeuropäische Netze, in: R. Bieber/A. Epiney/M. Haag/ M. Kotzur (Hrsg.), Die Europäische Union. Europarecht und Politik, Nomos, Baden-Baden, 12. Aufl. 2016, § 24 Rn. 5, wonach der EU-Gesetzgeber sowohl in zeitlicher als auch in inhaltlicher Hinsicht über ein weites Ermessen verfügt. Siehe auch C.D. Classen, in: T. Oppermann/C.D. Classen/M. Nettesheim, Europarecht, C.H. Beck, München, 8. Aufl. 2018, § 26, Rn. 7 und EuGH, Urteil vom 9. September 2004, verbundene Rechtssachen C-184/02 und C-223/02, Königreich Spanien und Republik Finnland gegen Europäisches Parlament und Rat der Europäischen Union, in: Sammlung der Rechtsprechung, 2004, S. I-7789 ff., Rn. 28, 29 und 30, ECLI:EU:C:2004:497; s. auch EuGH, Urteil vom 28. November 1978, Rs. 97/78, Fritz Schumalla, in: Sammlung der Rechtsprechung, 1978, S. 2311 ff., Rn. 4, ECLI:EU:C:1978:211 und EuGH, Urteil vom 17. Juli 1997, verbundene Rechtssachen C-248-95 und C-249-95, SAM Schifffahrt und Stapf gegen Bundesrepublik Deutschland, in: Sammlung der Rechtsprechung, 1997, I, S. 4475 ff., Rn. 23, ECLI:EU:C:1997:377.
} 
das in Art. 95 AEUV festgeschrieben wird: verboten sind Diskriminierungen, wonach ein Verkehrsunternehmen in denselben Verkehrsverbindungen für dieselben Güter je nach ihrem Herkunfts- oder Bestimmungsland unterschiedliche Frachten oder Beförderungsbedingungen anwendet.

\subsection{Regelungen zu öffentlichen Beihilfen}

Besondere Regelungen zum allgemeinen Beihilfeverbot ${ }^{47}$ finden sich in den Art. 93 und 96 AEUV, wo zugunsten der Besonderheiten des Verkehrs für gewisse Standorterfordernisse und die entsprechende Wirtschafts- und Wettbewerbspolitik Ausnahmetatbestände ermöglicht werden (sektorale Beihilfen). ${ }^{48}$ Die Abweichung vom generellen Beihilfeverbot im Bereich Verkehr, der als sensibler Sektor angesehen wird, ist damit zu rechtfertigen, dass im öffentlichen Interesse die Güter- und Personenbeförderung auch dann gewährleistet sein muss, wenn die Durchführung des Transports nicht in die Logik des Marktes fällt und nicht ausschließlich durch Wirtschafts- und Handelskriterien gesteuert werden kann. ${ }^{49}$

Abweichungen vom generellen Beihilfeverbot sind nur restriktiv und begrenzt möglich und müssen jedenfalls sowohl mit den Grundsätzen des Unionsrechts als auch mit den besonderen Regelungen im Bereich Beihilfen vereinbar sein. ${ }^{50}$

So sind Unterstützungsmaßnahmen von Unternehmen gemeinhin verboten, sofern nicht die Kommission eine entsprechende Genehmigung erteilt. Dabei hat die Kommission insbesondere die Kriterien einer angemessenen Standortpolitik, die Bedürfnisse unterentwickelter Gebiete, die Probleme der durch politische Umstände schwer betroffenen Gegenden sowie allfällige Auswirkungen der Beförderungsbedingungen auf den Wettbewerb zwischen den Verkehrsarten zu berücksichtigen.

Von besonderer Relevanz sind Unternehmen mit Konzessionen für den öffentlichen Personenverkehr. Sie erbringen Dienste ,von allgemeinem wirtschaftlichem

\footnotetext{
${ }^{47}$ Siehe Art. 107 AEUV.

${ }^{48}$ Instruktiv M. Haag, Staatliche Beihilfen, in: R. Bieber/A. Epiney/M. Haag/M. Kotzur (Hrsg.), Die Europäische Union. Europarecht und Politik, Nomos, Baden-Baden, 12. Aufl. 2016, § 13 Rn. 6 ff.; R. Bieber, in: ebenda, 2016, § 24 Rn. 8; Ph. Hafner, Entflechtung und Wettbewerb im Eisenbahnwesen. Europarechtliche Vorgaben, nationale Umsetzung, tatsächliche Situation, Dr. Kovač, Hamburg, 2011; C.D. Classen, in: T. Oppermann/C.D. Classen/M. Nettesheim, Europarecht, C.H. Beck, München, 8. Aufl. 2018, § 26, Rn. 19 ff.

${ }^{49}$ Vgl. R. Bieber/F. Maiani, Europäisches Verkehrsrecht. Die Rechtspraxis sämtlicher Verkehrsträger, Nomos, Baden-Baden, 2015, S. 552.

${ }^{50}$ Als Beispiel können die Beihilfen für Eisenbahnunternehmen genannt werden, die die Kosten des von ihnen für den Transport genutzten Eisenbahnnetzes tragen. Zudem werden Beihilfen an Logistikunternehmen oder multimodale Transportunternehmen gewährt, die auf Schienenverkehr setzen und somit den Straßenverkehr sowie die externen Kosten des Verkehrs wie Umweltverschmutzung, Lärm, Staus, Unfälle usw. reduzieren.
} 
Interesse innerhalb der gemeinsamen Werte der Union [...], [...und sind bedeutsam für die] Förderung des sozialen und territorialen Zusammenhalts ". ${ }^{51}$ Es ist daher nicht nur Interesse, sondern auch Aufgabe der Union und ihrer Mitgliedstaaten, dafür zu sorgen, dass diese Dienste stets im Einklang mit unionsrechtlichen Grundsätzen und Bedingungen erfolgen und eine effiziente Dienstleistungserbringung gesichert ist. ${ }^{52}$ Das öffentliche Eingreifen fällt nicht in den Anwendungsbereich von Art. 107 Abs. 1 AEUV, sondern dient als Ausgleich für die Leistungen, die von den empfangenden Unternehmen zur Erfüllung von Verpflichtungen des öffentlichen Dienstes erbracht werden. Demnach erhalten die Unternehmen keine finanziellen Vorteile und werden ebenso wenig in eine günstigere Wettbewerbsposition gegenüber den mit ihnen im Wettbewerb stehenden Unternehmen versetzt. ${ }^{53}$

Das Europäische Parlament und der Rat der EU haben darüber hinaus eine Reihe von Sonderbestimmungen auf sekundärer Ebene erlassen, um den Wettbewerb auf dem Verkehrsmarkt im Binnenmarkt zu regeln. ${ }^{54}$

\footnotetext{
${ }^{51}$ Vgl. Art. 14 AEUV.

${ }^{52}$ Vgl. Art. 106 Abs. 2 AEUV.

${ }^{53}$ Vgl. EuGH, Urteil vom 24. Juli 2003, Rs. C-280/00, Altmark Trans GmbH und Regierungspräsidium Magdeburg gegen Nahverkehrsgesellschaft Altmark GmbH, in: Sammlung der Rechtsprechung, 2003, S. I-07747, ECLI:EU:C:2003:415. Zum „Altmark“-Urteil siehe C.E. Baldi, La disciplina comunitaria degli aiuti di Stato. Manuale critico ad uso delle amministrazioni e delle imprese, Maggioli editore, Santarcangelo di Romagna, 2016, S. 398 ff.; zur Vertiefung vgl. M. Lehr, Beihilfen zur Gewährleistung des öffentlichen Personennahverkehrs: Die europarechtskonforme Finanzierung der Daseinsvorsorge am Beispiel des ÖPNV in Deutschland, Duncker \& Humblot, Berlin, 2011.

${ }^{54}$ Siehe dazu Verordnung (EU) Nr. 651/2014 der Kommission vom 17. Juni 2014 zur Feststellung der Vereinbarkeit bestimmter Gruppen von Beihilfen mit dem Binnenmarkt in Anwendung der Artikel 107 und 108 des Vertrags über die Arbeitsweise der Europäischen Union, in: Abl., 26. Juni 2014, L 187, S. 1 ff., ELI: http://data.europa.eu/eli/reg/2014/651/oj (21.08.2021); Verordnung (EG) Nr. 169/2009 des Rates vom 26. Februar 2009 über die Anwendung von Wettbewerbsregeln auf dem Gebiet des Eisenbahn-, Straßen- und Binnenschiffsverkehrs, in: Abl., 5. März 2009, L 61, S. 1 ff., ELI: http://data.europa.eu/eli/reg/2009/169/oj (21.08.2021); Verordnung (EG) Nr. 1370/2007 des Europäischen Parlaments und des Rates vom 23. Oktober 2007 über öffentliche Personenverkehrsdienste auf Schiene und Straße und zur Aufhebung der Verordnungen (EWG) Nr. 1191/69 und (EWG) Nr. 1107/70 des Rates, in: Abl., 3. Dezember 2007, L 315, S. 1 ff., ELI: http://data.europa.eu/eli/reg/2007/1370/oj (21.08.2021); Verordnung (EG) Nr. 718/1999 über kapazitätsbezogene Maßnahmen für die Binnenschifffahrtsflotten der Gemeinschaft zur Förderung des Binnenschiffsverkehrs, in: Abl., 2. April 1999, L 90, S. 1 ff., ELI: http://data.europa.eu/eli/ reg/1999/718/oj (21.08.2021); Verordnung (EWG) Nr. 4057/86 des Rates vom 22. Dezember 1986 über unlautere Preisbildungspraktiken im Seeverkehr, in: Abl., 31. Dezember 1986, L 378, S. 14 ff., ELI: http://data.europa.eu/eli/reg/1986/4057/oj (21.08.2021); Verordnung (EWG) Nr. 4058/86 des Rates vom 22. Dezember 1986 für ein koordiniertes Vorgehen zum Schutz des freien Zugangs zu Ladungen in der Seeschifffahrt, in: Abl., 31. Dezember 1986, L 378, S. 21 ff., ELI: http://data.europa.eu/eli/reg/1986/4058/oj (21.08.2021).
} 


\subsection{Querschnittsmaterien}

Rein methodisch darf daran erinnert werden, dass jenseits der Vorschriften, die in Titel VI (Art. 90-100) und in Titel XVI (Art. 170-172) des dritten Teils des AEUV vorgesehen sind, auch für die gemeinsame Verkehrspolitik im Binnenmarkt alle allgemeinen Rechtsprinzipien des EU-Primärrechts gelten.

Eine besondere Erwähnung verdienen in diesem Zusammenhang die Dienstleistungsfreiheit, ${ }^{55}$ die Warenverkehrsfreiheit, ${ }^{56}$ die Niederlassungsfreiheit, ${ }^{57}$ das Diskriminierungsverbot aufgrund der Staatsangehörigkeit, ${ }^{58}$ die Wettbewerbsregeln ${ }^{59}$ und das Beihilfenrecht sowie die Aufhebung der Grenzkontrollen im unionsrechtlichen Binnenbereich. ${ }^{60}$

\section{Sekundärrechtliche Ausgestaltung der EU-Verkehrspolitik}

Zur gemeinsamen Verkehrspolitik findet sich eine Vielzahl an Sekundärrechtsakten. ${ }^{61}$ Das erklärt sich zunächst mit Blick auf die Ausgestaltung von Art. 100 AEUV, der insgesamt fünf verschiedenartige Verkehrsträger - Eisenbahn, ${ }^{62}$ Straßen,

\footnotetext{
${ }^{55}$ Art. 58 Abs. 1 AEUV.

${ }^{56}$ Art. 34 AEUV. Zum Fahrverbot für Lastkraftwagen auf der Brennerautobahn aus Umweltschutzgründen in Widerspruch zum freien Warenverkehr vgl. EuGH, Urteil vom 15. November 2005, Rs. C-320/03, Kommission der Europäischen Gemeinschaften gegen Republik Österreich, in: Sammlung der Rechtsprechung, 2005, S. I-09871 ff., ECLI:EU:C:2005:684 und EuGH, Urteil vom 21. Dezember 2011, Rs. C-28/09, Europäische Kommission gegen Republik Österreich, in: Sammlung der Rechtsprechung, 2011, I, S. 13525 ff., ECLI:EU:C:2011:854.

${ }^{57}$ Art. 49 AEUV; siehe EuGH, Urteil vom 22. Dezember 2010, Rs. C-338/09, Yellow Cab Verkehrsbetriebs $\mathrm{GmbH}$ gegen Landeshauptmann von Wien, in: Sammlung der Rechtsprechung, 2010, I, S. 13827 ff., ECLI:EU:C:2010:814.

${ }^{58}$ Art. 18 AEUV; siehe EuGH, Urteil vom 18. März 2014, Rs. C-628/11, Strafverfahren gegen International Jet Management $\mathrm{GmbH}$, in: Sammlung der Rechtsprechung, 2014, ECLI:EU:C:2014:171 und EuGH, Urteil vom 25. Januar 2011, Rs. C-382/08, Michael Neukirchinger gegen Bezirkshauptmannschaft Grieskirchen, in: Sammlung der Rechtsprechung, 2011, I, S. 139 ff., ECLI:EU:C:2011:27.

${ }^{59}$ EuGH, Urteil vom 4. April 1974, Rs. 167/73, Kommission der Europäischen Gemeinschaften gegen Französische Republik, in: Sammlung der Rechtsprechung, 1973, S. 359 ff., ECLI:EU:C:1974:35.

${ }^{60}$ Vgl. C.D. Classen, in: T. Oppermann/C.D. Classen/M. Nettesheim, Europarecht, C.H. Beck, München, 8. Aufl. 2018, § 26 Rn. 9 f. m.w.N.

${ }^{61} \mathrm{Vgl}$. beispielsweise die Aufzählung der sekundärrechtlichen Maßnahmen der Gemeinsamen Verkehrspolitik mit Schwerpunkt auf die Liberalisierung des Schienenverkehrs bei M. Krajewski, Grundstrukturen des Rechts öffentlicher Dienstleistungen, Springer, Berlin-Heidelberg, 2011, S. $234 \mathrm{ff}$

${ }^{62}$ Nach E. Brandt, Verkehrspolitik und transeuropäische Netze, in: M. Röttinger/C. Weyringer (Hrsg.), Handbuch der europäischen Integration, Manz, Wien, 2. Aufl. 1996, S. 917 (923) bildete die Eisenbahn das „Sorgenkind der europäischen Verkehrspolitik“).
} 
Binnenschifffahrt, Seeschifffahrt, Luftfahrt - in einer Norm zusammenfasst, sodass in den jeweiligen Rechtsakten nur jeweils ein bestimmter Verkehrsträger angesprochen wird. Außerdem sind die Unterschiede in den jeweiligen Regelungsansprüchen zu beachten, so etwa, wenn man den überwiegend privaten Straßenverkehr dem größtenteils staatsnahen Eisenbahnverkehr gegenüberstellen möchte. Schließlich werden in der gemeinsamen Verkehrspolitik durchaus unterschiedliche Zielsetzungen verfolgt, etwa einerseits Marktöffnung und Liberalisierung im Binnenmarkt, andererseits Sicherstellung fairer Wettbewerbsbedingungen, aber auch Rechtsangleichung in Verbindung mit dem vorgegebenen Ziel der Verkehrssicherheit.

\subsection{Liberalisierung des Verkehrs}

Im Hinblick auf die Marktliberalisierung im Verkehrssektor muss zwischen den verschiedenen Verkehrsarten, d. h. dem Schienen-, Straßen- und Binnenschiffsverkehr sowie dem See- und Luftverkehr, unterschieden werden. Sie weisen nämlich grundlegende Unterschiede auf, die meist auf bestimmte historische Entwicklungen zurückzuführen sind. Während beispielsweise der Verkehr von PKWs, LKWs und Anhängern immer schon in privaten Händen lag, wird das Eisenbahnwesen in den meisten Mitgliedstaaten von öffentlichen Unternehmen geführt, meist unter indirekter oder direkter Kontrolle des Staates. Der See- und Luftverkehr wurden hingegen seit jeher stark von internationalen Vorschriften geprägt.

Im Detail lassen sich innerhalb der sekundärrechtlichen Bestimmungen grundsätzlich drei Liberalisierungstendenzen feststellen.

Bei der Erbringung von Verkehrsdienstleistungen wurde durch das Sekundärrecht eine Vielzahl von Beschränkungen, etwa zur Kontingentbildung, Preisregelung oder zum Kabotageverbot, aufgehoben. ${ }^{63}$

Im Rahmen des Schienenverkehrs liegen Schwerpunkte des Sekundärrechts u.a. bei der Kompatibilität des Zugmaterials, der Abstimmung der Gleisverbindungen und grenzüberschreitenden Streckenzügen. Außerdem sollen Maßnahmen den diskriminierungsfreien Zugang zum Bahnnetz sowie zur entsprechenden Infrastruktur sichern. Insbesondere hat die Kommission hier gegen verschiedene Mitgliedstaaten Vertragsverletzungsverfahren angestrengt, die allerdings nur zum Teil erfolgreich waren. ${ }^{64}$

\footnotetext{
${ }^{63}$ Siehe Art. 91 Abs. 1 lit. b) AEUV; siehe zudem Verordnung (EWG) Nr. 3118/93 des Rates vom 25. Oktober 1993 zur Festlegung der Bedingungen für die Zulassung von Verkehrsunternehmen zum Güterkraftverkehr innerhalb eines Mitgliedstaats, in dem sie nicht ansässig sind, in: Abl., 12. November 1993, L 279, S. 1 ff., ELI: http://data.europa.eu/eli/reg/1993/3118/oj (21.08.2021) und insb. Art. 8, § 2 Verordnung (EG) Nr. 1072/2009 des Europäischen Parlaments und des Rates vom 21. Oktober 2009 über gemeinsame Regeln für den Zugang zum Markt des grenzüberschreitenden Güterkraftverkehrs, in: Abl., 14. November 2009, L 300, S. 72 ff., ELI: http://data.europa.eu/eli/ reg/2009/1072/oj (21.08.2021) bzgl. der sog. exekutive Kabotagebeförderung.

${ }^{64}$ Vgl. etwa das Verfahren EuGH, Urteil vom 28. Februar 2013, Rs. C-556/10, Europäische Kommission gegen Bundesrepublik Deutschland, ECLI:EU:C:2013:116.
} 
Mit Blick auf die Luftfahrt findet sich sekundäres Unionsrecht zu den Zeitrahmen bei Start- und Landemöglichkeiten auf Flughäfen, ${ }^{65}$ aber auch zum Zugang zu den Bodenabfertigungsdiensten am Flughafen. ${ }^{66} 2004$ wurde über das Sekundärrecht zudem die Erbringung von Flugsicherungsdiensten, die Ordnung und die Nutzung des EU-Luftraums und das Flugverkehrsmanagement-Netz europäisiert. ${ }^{67}$

Im Rahmen der Liberalisierung personenbezogener Regelungen ist insbesondere der europäische Führerschein zu nennen. ${ }^{68}$ Dabei verfolgt die Union einerseits das Ziel, mit dem Verkehrsbereich die allgemeine Personenfreizügigkeit zu ergänzen, andererseits soll verhindert werden, dass Verkehrsverstöße durch transnationale Vorgehensweisen sanktionsfrei bleiben. Die Europäische Union hat dafür mittels einer Richtlinie, die den Mitgliedstaaten einen gewissen Handlungsspielraum bei der Umsetzung ließ, ein einheitliches Modell des Führerscheins eingeführt, das die Informationen festlegt, welche in einem Genehmigungsdokument dieser Art unbedingt enthalten sein müssen. Des Weiteren werden darin die Voraussetzungen und Mindesterfordernisse für seine Ausstellung definiert. Ziel ist es, eine sichere Fahrt auf europäischen Straßen zu gewährleisten, unabhängig davon, von welchem Mitgliedstaat der Führerschein ausgestellt wurde. ${ }^{69}$

Im Zuge der Bereitstellung und Nutzung von Infrastruktur findet insbesondere das Diskriminierungsverbot in seiner allgemeinen Ausgestaltung ${ }^{70}$ bzw. bezogen auf Verkehrsunternehmen ${ }^{71}$ Niederschlag. Dieses Thema ist heute in der EU von besonderer Aktualität. Grundlegend wird dabei zwischen einer Mautgebühr, d. h. einer Gebühr für die Nutzung einer bestimmten Strecke auf einer Autobahn (z. B.

\footnotetext{
${ }^{65}$ Vgl. nunmehr Verordnung (EWG) Nr. 95/93 des Rates vom 18. Januar 1993 über gemeinsame Regeln für die Zuweisung von Zeitnischen auf Flughäfen in der Gemeinschaft, in: Abl., 22. Januar 1993, L 14/1, S. 1 ff., ELI: http://data.europa.eu/eli/reg/1993/95/oj (21.08.2021).

${ }^{66}$ S. Richtlinie 96/97/EG des Rates vom 15. Oktober 1996 über den Zugang zum Markt der Bodenabfertigungsdienste auf den Flughäfen der Gemeinschaft, in: Abl., 25. Oktober 1996, L 272, S. 36 ff., ELI: http://data.europa.eu/eli/dir/1996/67/oj (21.08.2021).

${ }^{67}$ S. Verordnung (EG) Nr. 550/2004 des Europäischen Parlaments und des Rates vom 10. März 2004 über die Erbringung von Flugsicherungsdiensten im einheitlichen europäischen Luftraum („Flugsicherungsdienste-Verordnung“), in: Abl., 31. März 2004, L 96, S. 10 ff., ELI: http://data. europa.eu/eli/reg/2004/550/oj (21.08.2021); Verordnung (EG) Nr. 551/2004 des Europäischen Parlaments und des Rates vom 10. März 2004 über die Ordnung und Nutzung des Luftraums im einheitlichen europäischen Luftraum („Luftraum-Verordnung“), in: Abl., 31. März 2004, L 96, S. 20 ff., ELI: http://data.europa.eu/eli/reg/2004/551/oj (21.08.2021); Verordnung (EG) Nr. 552/2004 des Europäischen Parlaments und des Rates vom 10. März 2004 über die Interoperabilität des europäischen Flugverkehrsmanagementnetzes („Interoperabilitäts-Verordnung“), in: Abl., 31. März 2004, L 96, S. 26, ELI: http://data.europa.eu/eli/reg/2004/552/oj (21.08.2021).

${ }^{68}$ S. Richtlinie Nr. 2006/126/EG des Europäischen Parlaments und des Rates vom 20. Dezember 2006 über den Führerschein, in: Abl., 30. Dezember 2006, L 403, S. 18 ff., ELI: http://data.europa. eu/eli/dir/2006/126/oj (21.08.2021).

${ }^{69} \mathrm{Vgl}$. https://ec.europa.eu/transport/road_safety/topics/driving-licence/eu-driving_licence_de (21.08.2021).

${ }^{70}$ Vgl. Art. 18 AEUV.

${ }^{71}$ Vgl. Art. 92 AEUV. Die praktische Bedeutung dieser Norm ist beschränkt, der EU-Gesetzgeber hat aufgrund von Art. 91 Abs. 1 AEUV eine ganze Reihe von sekundärrechtlichen Bestimmungen erlassen.
} 
„pedaggio“ in Italien), und einer Benutzungsgebühr, d. h. einer Gebühr, um für einen festgelegten Zeitraum die Autobahn nutzen zu können (z. B. „Vignette“ in Österreich), unterschieden. ${ }^{72}$

Das erstgenannte Modell sieht vor, dass die Infrastrukturen gegen die Zahlung einer Gebühr an den Betreiber, bei dem es sich um den Staat selbst, eine öffentliche Körperschaft oder sogar ein privates Unternehmen handeln kann, genutzt werden können. Die Gebühr wird nach der zurückgelegten Strecke und der Art des verwendeten Fahrzeugs oder sogar pauschal, aber immer nur für die tatsächlich erfolgte Nutzung, berechnet. ${ }^{73}$

Beim System der Benutzungsgebühr wird ein Betrag als einmalige Zahlung für einen bestimmten Zeitraum entrichtet (z. B. für einen Tag, eine Woche, ein Monat oder ein Jahr), unabhängig davon, wie viele Kilometer auf der jeweiligen Autobahn zurückgelegt wurden. ${ }^{74}$ Dieses Modell kann jedoch diskriminierende Elemente für ausländische Nutzer enthalten, zumal die Infrastrukturen von nicht im betreffenden Staat ansässigen Personen in der Regel nicht so häufig und intensiv genutzt werden wie von Personen, die im jeweiligen Staat leben und arbeiten. Es fällt Nichtansässigen demnach schwerer, die entsprechenden Begünstigungen und Dienste in Verbindung mit der Vignette zu beanspruchen.

Ein konkretes Beispiel für die Verletzung des EU-Diskriminierungsverbots stellt die Infrastrukturabgabe, besser bekannt als PKW-Maut, dar, die in Deutschland am 1. Januar 2016 eingeführt wworden war und nach Ansicht führender Politiker durch Kompensation über eine niedrige Kfz-Steuer faktisch nur ausländische PKW-Fahrer treffen sollte. ${ }^{75}$ Die große Kammer des EuGHs entschied mit Urteil vom 18. Juni 2019 die Rechtssache C-591/17, ${ }^{76}$ die von der Republik Österreich ${ }^{77}$ gegen die Bundesrepublik Deutschland angestrengt worden war und mit einer juristischen

\footnotetext{
${ }^{72}$ Siehe allgemein C.D. Classen, in: T. Oppermann/C.D. Classen/M. Nettesheim, Europarecht, C.H. Beck, München, 8. Aufl. 2018, § 26 Rn. 13 ff.

${ }^{73}$ Dieses System wird z. B. in Frankreich, Spanien, Portugal, Irland, Griechenland, Norwegen und Polen angewandt.

${ }^{74}$ Dieses System wird z. B. in Österreich, der Schweiz, Slowenien, Ungarn, Rumänien, Bulgarien, Tschechien und der Slowakei angewandt. In einigen EU-Ländern ist die Nutzung der Autobahnen für Autos kostenlos, z. B. in Deutschland, Luxemburg, Belgien, den Niederlanden, Dänemark, Schweden, Finnland usw.

${ }^{75}$ Zur Thematik vgl. F. Kainer, Deutsche Pkw-Maut vor dem EuGH, in: GPR, 2015, S. 261 ff.; M. Legath, Die deutsche Pkw-Maut und Art. 92 AEUV, in: ZVR, 2017, S. 192 ff.

${ }^{76}$ In: Abl., 12. August 2019, C 270, S. 4 f.

${ }^{77}$ Es ist außergewöhnlich, dass ein Mitgliedstaat beim EuGH eine Vertragsverletzungsklage gegen einen anderen Mitgliedstaat einreicht. Der Gerichtshof hat zwar längst mehr als 30.000 Rechtssachen bearbeitet, aber nur in acht Fällen in der Geschichte des Gerichtshofs hat ein Mitgliedstaat eine Vertragsverletzungsklage gegen einen anderen Mitgliedstaat eingereicht. Abgesehen von der oben genannten Rechtssache, wurden nur folgende vier mit einem Urteil abgeschlossen: Rs. 141/78: Frankreich gegen Vereinigtes Königreich; Rs. 388/95: Belgien gegen Spanien; Rs. 145/04: Spanien gegen Vereinigtes Königreich; Rs. 364/10: Ungarn gegen Slowakei; Rs. 457/18: Slowenien gegen Kroatien.
} 
Niederlage Deutschlands endete. ${ }^{78}$ Die Hintergründe dieses Urteils ${ }^{79}$ sind auf das Jahr 2015 zurückzuführen, als Deutschland den Gesetzestext zur Einführung einer Gebühr für die Nutzung von Bundesstraßen und Autobahnen seitens privater Fahrzeuge ausarbeitete. Alle Eigentümer von Fahrzeugen mit Registrierung in Deutschland, hätten die Abgabe in Form einer jährlichen Marke zahlen müssen. Hinsichtlich außerhalb Deutschlands registrierter Fahrzeuge, hätte die Infrastrukturabgabe vom Eigentümer oder vom Fahrzeuglenker bezahlt werden müssen, sobald diese die Autobahn benutzt hätten. Gleichzeitig wäre aber durch die Entrichtung der Infrastrukturabgabe die Kfz-Steuer für die Eigentümer der in Deutschland zugelassenen Fahrzeuge um die von ihnen gezahlte Gebühr gekürzt worden. Österreich beklagte, dass die kombinierte Wirkung von Infrastrukturabgabe und Kürzung der Kfz-Steuer für in Deutschland zugelassene Fahrzeuge sowie die Art und Weise, auf die die Infrastrukturabgabe festgelegt und angewandt worden war, gegen EU-Recht, insbesondere gegen das Verbot der Diskriminierung aufgrund der Staatsangehörigkeit, verstoße. Nachdem von der Kommission eine Stellungnahme gefordert wurde, die nicht fristgerecht abgegeben wurde ${ }^{80}$ erhob Österreich beim Gerichtshof eine Vertragsverletzungsklage gegen Deutschland. ${ }^{81}$ In seinem Urteil stellte der Gerichtshof - unter Verweis darauf, dass Deutschland gegen seine Verpflichtungen aus Art. 18, 34, 56 und 92 AEUV verstoßen habe - fest, dass die Infrastrukturabgabe in Verbindung mit der Verringerung der Kfz-Steuer die Eigentümer von in Deutschland zugelassenen Fahrzeugen begünstige, eine mittelbare Diskriminierung aufgrund der Staatsangehörigkeit und einen Verstoß gegen die Grundsätze des freien Waren- und Dienstleistungsverkehrs darstelle. In Bezug auf das Verbot der Diskriminierung aufgrund der Staatsangehörigkeit stellte der Gerichtshof fest, dass die Befreiung von der Kfz-Steuer zugunsten der Eigentümer von in Deutschland zugelassenen Fahrzeugen einen vollständigen Ausgleich der von ihnen gezahlten Infrastrukturabgaben bewirken würde. Somit würde die wirtschaftliche Belastung

\footnotetext{
${ }^{78}$ Zur Thematik vgl. F. Kainer, Deutsche PKW-Maut vor dem EuGH, in: GPR, 2015, S. 261 ff.; M. Legath, Die deutsche Pkw-Maut und Art. 92 AEUV, in: ZVR, 2017, S. 192 ff.; L. Beck, Autobahnmaut und Europarecht, in: NZV, 2014, S. 289 ff.; K.-H. Danzl, Pkw-Maut in Deutschland EU-rechtskonform?, in: ZVR, 2017, S. 189 ff.; S. Korte/M. Gurreck, Die europarechtliche Zulässigkeit der sog. PKW-Maut, in: EuR, 2014, S. 420 ff.; S. Hartmann, Die Vereinbarkeit der Pkw-Maut mit dem Recht der Europäischen Union, Ergon Verlag, Würzburg, 2016.

${ }^{79}$ Zur Beschreibung des Sachverhalts vgl. Gerichtshof der Europäischen Union, Pressemitteilung Nr. 75/19, Luxemburg, den 18 Juni 2019: Urteil in der Rechtssache C-591/17, Österreich gegen Deutschland, online unter https://curia.europa.eu/jcms/upload/docs/application/pdf/2019-06/ cp190075de.pdf (21.08.2021).

${ }^{80}$ In der Tat hatte die Kommission Kompromissvorschläge für mehrere Kurzzeitvignetten für ausländische Autos geprüft; vgl. A. Kruhl, Nachbesserungen bei der Pkw-Maut - ein aktueller Überblick, in: NZV, 2017, S. 167 ff. Schließlich hatte sie jedoch grünes Licht für die PKW-Maut gegeben; vgl. Europäische Kommission, Pressemitteilung, 01.12.2016: EU-Kommission und Deutschland einigen sich auf gerechte und diskriminierungsfreie Maut, online unter https:// ec.europa.eu/commission/presscorner/detail/de/IP_16_4221 (21.08.2021).

${ }^{81}$ In dem Verfahren wurde Österreich von den Niederlanden unterstützt, während Deutschland von Dänemark unterstützt wurde.
} 
durch diese Abgabe in der Tat ausschließlich auf ausländischen PKW-Fahrern lasten. ${ }^{82}$

Während das Schrifttum von einer Unionsrechtswidrigkeit ausgegangen war, ${ }^{83}$ gab die Europäische Kommission nach Prüfung eines nachgebesserten Kompromissvorschlags, der für ausländische PKWs verschieden gestaffelte Kurzzeitvignetten vorsah, ${ }^{84}$ letztlich grünes Licht für die PKW-Maut, da sie den Grundsatz der Gleichbehandlung der EU-Bürger ungeachtet ihrer Staatsbürger beachte, für eine gerechte Infrastrukturfinanzierung sorge und den Übergang zu einer emissionsarmen Mobilität erleichtere. ${ }^{85}$

\subsection{Sicherung des Wettbewerbs}

Ein besonderes Augenmerk der EU-Verkehrspolitik bildet die Sicherung des Wettbewerbes. Hierbei werden verschiedene Aspekte schlagend.

So ist zunächst das Beihilfenrecht zu nennen, das in Art. 93 AEUV verschiedene Ausnahmetatbestände enthält, die auf bestimmte Erfordernisse des Verkehrs oder die Abgeltung besonderer öffentlicher Dienstleistungen ${ }^{86}$ abzielen.

\footnotetext{
${ }^{82}$ Anmerkungen zum Urteil: R. Pracht, Primärrechtswidrigkeit der Pkw-Maut, in: ZJS, 5, 2019, S. 425 ff.; M. Seyfarth, Das Urteil des Europäischen Gerichtshofs zur Infrastrukturabgabe - eine Urteilsanmerkung, in: Straßenverkehrsrecht, 8, 2019, S. 285 ff.

${ }^{83}$ Vgl. etwa L. Beck, Autobahnmaut und Europarecht, in: NZV, 2014, S. 289 ff.; K.-H. Danzl, PkwMaut in Deutschland - EU-rechtskonform?, in: ZVR, 2017, S. 189 ff.; S. Korte/M. Gurreck, Die europarechtliche Zulässigkeit der sog. Pkw-Maut, in: EuR, 2014, S. 420 ff.; monografisch etwa S. Hartmann, Die Vereinbarkeit der Pkw-Maut mit dem Recht der Europäischen Union, Ergon Verlag, Würzburg, 2016.

${ }^{84}$ Siehe dazu A. Kruhl, Nachbesserungen bei der Pkw-Maut - ein aktueller Überblick, in: NZV, 2017, S. $167 \mathrm{ff}$.

${ }^{85} \mathrm{Vgl}$. Europäische Kommission, Pressemitteilung, 01.12.2016: EU-Kommission und Deutschland einigen sich auf eine gerechte und diskriminierungsfreie Maut, online: https://ec.europa.eu/ commission/presscorner/detail/de/IP_16_4221 (21.08.2021).

${ }^{86}$ Nach herrschender Rechtsprechung des Gerichtshofes der Europäischen Union stellt eine staatliche oder öffentliche Maßnahme im Bereich des öffentlichen Personennahverkehrs (ÖPNV) keine Verletzung des Beihilfeverbotes dar, wenn sie als Ausgleich anzusehen ist, der die Gegenleistung für Leistungen bildet, die von den Unternehmen, denen sie zugutekommt, zur Erfüllung gemeinwirtschaftlicher Verpflichtungen erbracht werden. Die genannte Gegenleistung stellt somit für das Unternehmen in Wirklichkeit keinen finanziellen Vorteil dar und die genannte Maßnahme bewirkt somit nicht, dass sie gegenüber den mit ihnen im Wettbewerb stehenden Unternehmen in eine günstigere Wettbewerbsstellung gelangen. Ein derartiger Ausgleich ist im konkreten Fall jedoch nur dann nicht als verbotene staatliche Beihilfe zu qualifizieren, wenn folgende Voraussetzungen erfüllt sind: (1) Das begünstigte Unternehmen muss tatsächlich mit der Erfüllung gemeinwirtschaftlicher Verpflichtungen betraut sein und diese Verpflichtungen müssen klar definiert sein. (2) Die Parameter, anhand deren der Ausgleich berechnet wird, sind zuvor objektiv und transparent aufzustellen, um zu verhindern, dass der Ausgleich einen wirtschaftlichen Vorteil mit sich bringt, der das Unternehmen, dem er gewährt wird, gegenüber konkurrierenden Unternehmen begünstigt. (3) Der Ausgleich darf nicht über das hinausgehen, was erforderlich ist, um die Kosten der Erfüllung der gemeinwirtschaftlichen Verpflichtungen unter Berücksichtigung der dabei erzielten
} 
Für den Eisenbahn-, Straßen- und Schiffsverkehr werden im Sekundärrecht spezielle Wettbewerbsregeln aufgestellt, die auf die Besonderheiten des Verkehrs Rücksicht nehmen. ${ }^{87}$ Diese betreffen gerade im Bereich der öffentlichen Personenverkehrsdienste die jeweiligen Vergabeverfahren. Die entsprechenden Vorschriften lehnen sich zwar teilweise an die Bestimmungen für die Vergabe öffentlicher Aufträge an, belassen den Mitgliedstaaten im Einzelnen aber mehr Spielraum. ${ }^{88}$

Nichtsdestotrotz erfolgte die Vergabe von Diensten im Bereich des öffentlichen Personenverkehrs über viele Jahrzehnte in vielen Mitgliedstaaten nicht im Wege öffentlicher Ausschreibungen, sondern es wurden Konzessionen ohne Ausschreibung ausgestellt. Dieser Umstand ist sicherlich auch darauf zurückzuführen, dass der öffentliche Personenverkehr in vielen Mitgliedstaaten von staatlichen oder zumindest öffentlichen Unternehmen beherrscht wurde bzw. wird.

Schließlich sind verschiedene Standards für die Beschäftigten und die Nutzer im Verkehrssektor zu nennen.

Einnahmen und eines angemessenen Gewinns aus der Erfüllung dieser Verpflichtungen ganz oder teilweise zu decken. Nur bei Einhaltung dieser Voraussetzung ist gewährleistet, dass dem betreffenden Unternehmen kein Vorteil gewährt wird, der dadurch, dass er die Wettbewerbsstellung dieses Unternehmens stärkt, den Wettbewerb verfälscht oder zu verfälschen droht. (4) Wenn die Wahl des Unternehmens, das mit der Erfüllung gemeinwirtschaftlicher Verpflichtungen betraut werden soll, im konkreten Fall nicht im Rahmen eines Verfahrens zur Vergabe öffentlicher Aufträge erfolgt, das die Auswahl desjenigen Bewerbers ermöglicht, der diese Dienste zu den geringsten Kosten für die Allgemeinheit erbringen kann, so ist die Höhe des erforderlichen Ausgleichs auf der Grundlage einer Analyse der Kosten zu bestimmen, die ein durchschnittliches, gut geführtes Unternehmen, das so angemessen mit Transportmitteln ausgestattet ist, dass es den gestellten gemeinwirtschaftlichen Anforderungen genügen kann, bei der Erfüllung der betreffenden Verpflichtungen hätte. Die dabei erzielten Einnahmen und ein angemessener Gewinn aus der Erfüllung dieser Verpflichtungen sind zu berücksichtigen (,Altmark-Kriterien“), siehe im konkreten: EuGH, Urteil vom 24. Juli 2003, Rs. C-280/00: Altmark Trans GmbH und Regierungspräsidium Magdeburg gegen Nahverkehrsgesellschaft Altmark GmbH, Beteiligte: Oberbundesanwalt beim Bundesverwaltungsgericht, in: Sammlung der Rechtsprechung, 2003, S. I-07747 (im Speziellen Rn. 87-93, Tenor 2); ECLI:EU:C:2003:415; Urteilsanmerkung: E. Scotti, Brevi note in tema di servizi pubblici e aiuti di Stato, in: Il Foro amministrativo, 2003, 2, S. 3219 ff.; N. Travers, Public Service Obligations and State Aid: Is all really clear after Altmark?, in: European State Aid Law Quarterly, 2, 2003, S. 387 ff.; F. Louis/A. Vallery, Ferring Revisited: the Altmark Case and State Financing of Public Service Obligations, in: World Competition, 1, 2004, S. 53 ff.; A. Fratini/F. Filpo, I nuovi sviluppi giurisprudenziali sul concetto di aiuto di Stato: dalla formula Altmark al paradosso del monopolista-concorrente di Chronopost, in: Contratto e impresa/Europa, 2, 2003, S. 1183 ff.; E. Zanelli, Servizio pubblico e sentenza Altmark, in: Politica del diritto, 1, 2004, S. 175 ff.; R. Magliano, Servizi di interesse economico generale, aiuti di stato e compensazione di oneri di servizio pubblico: giurisprudenza Altmark e iniziative normative della commissione CE, in: Diritto del commercio internazionale, 3, 2004, S. 790 ff.; M. Antonисci, I servizi di interesse economico generale e gli aiuti di stato. Nota a sentenza C-280/00 della Corte di giustizia C.E., in: Il Consiglio di Stato, 2003, II, S. 1356 ff.

${ }^{87}$ Verordnung (EG) Nr. 169/2009 des Rates vom 26. Februar 2009 über die Anwendung von Wettbewerbsregeln auf dem Gebiet des Eisenbahn-, Straßen- und Binnenschiffverkehrs, in: Abl., 5. März 2009, L 61, S. 1, ELI: http://data.europa.eu/eli/reg/2009/169/oj (21.08.2021).

${ }^{88}$ Ausführlich M. Nettesheim, Das neue Dienstleistungsrecht des ÖPNV - Die Verordnung (EG) Nr. 1370/2007, in: NVwZ, 2009, S. 1449 ff. 
Hinsichtlich der Beschäftigten gilt es auf die Sozialvorschriften im Straßenverkehr zu verweisen, die etwa das Mindestalter von LKW-Fahrern, die Lenk- und Ruhezeiten im Straßengüterverkehr oder auch das Verbot von einzelnen leistungsbezogenen Entgelten vorsehen. ${ }^{89}$

Mit Blick auf die Nutzer bzw. Verbraucher sind die besonderen Fahrgastrechte zu nennen, ${ }^{90}$ etwa im Hinblick auf Überbuchungen, Verspätungen oder Ausfälle von Fahrten und Flügen, auf die Rechte behinderter Fluggäste, aber auch auf die Unfallhaftung. ${ }^{91}$

\subsection{Verkehrssicherheit}

Besondere praktische Bedeutung kommt dem Schwerpunkt der Verkehrssicherheit zu, zumal es in der EU jährlich etwa 50.000 Verkehrstote und rund 1,5 Millionen Verletzte gibt. ${ }^{92}$

\footnotetext{
${ }^{89}$ Verordnung (EG) Nr. 561/2006 des Europäischen Parlaments und des Rates vom 15. März 2006 zur Harmonisierung bestimmter Sozialvorschriften im Straßenverkehr und zur Änderung der Verordnungen (EWG) Nr. 3821/85 und (EG) Nr. 2135/98 des Rates sowie zur Aufhebung der Verordnung (EWG) Nr. 3820/85 des Rates, in: Abl., 11. April 2006, L 102, S. 1 ff., ELI: http://data. europa.eu/eli/reg/2006/561/oj (21.08.2021).

${ }^{90}$ Siehe M. Krüger, Die Passagierrechte im Flug-, Bahn-, Schiffs- und Busverkehr: Gemeinsamkeiten und Unterschiede der vier EG-Verordnungen und Vereinbarkeit dieser bei der enthaltenen Entschädigungszahlung mit dem Grundsatz der Gleichbehandlung nach Art. 20 GRC, Jenaer Wissenschaftliche Verlag, Jena, 2016; A. Staudinger/St. Keiler (Hrsg.), Die Fluggastrechte-Verordnung. Handkommentar, Nomos, Baden-Baden 2016; D. Faulenbach, Fahrgastrechte bei Zugverspätungen, in: NZV 2005, S. 398 ff.

${ }^{91}$ Vgl. C.D. Classen, in: T. Oppermann/C.D. Classen/M. Nettesheim, Europarecht, C.H. Beck, München, 8. Aufl. 2018, § 26 Rn. 24 m.w.N. Siehe zum Eisenbahnsektor: Verordnung (EG) Nr. 1371/2007 des Europäischen Parlaments und des Rates vom 23. Oktober 2007 über die Rechte und Pflichten der Fahrgäste im Eisenbahnverkehr, in: Abl., 3. Dezember 2007, L 315, S. 14 ff., ELI: http://data.europa.eu/eli/reg/2007/1371/oj (21.08.2021); zum Luftverkehr: Verordnung (EG) Nr. 261/2004 des Europäischen Parlaments und des Rates vom 11. Februar 2004 über eine gemeinsame Regelung für Ausgleichs- und Unterstützungsleistungen für Fluggäste im Fall der Nichtbeförderung und bei Annullierung oder großer Verspätung von Flügen und zur Aufhebung der Verordnung (EWG) Nr. 295/91, in: Abl., 17. Februar 2004, L 46, S. 1 ff., ELI: http://data. europa.eu/eli/reg/2004/261/oj (21.08.2021); zu Wasserstraßen und Seeschifffahrt: Verordnung (EU) Nr. 1177/2010 des Europäischen Parlaments und des Rates vom 24. November 2010 über die Fahrgastrechte im See- und Binnenschiffverkehr und zur Änderung der Verordnung (EG) Nr. 2006/2004, in: Abl., 17. Dezember 2010, L 334, S. 1 ff., ELI: http://data.europa.eu/eli/ reg/2010/1177/oj (21.08.2021); zum Straßenpersonenverkehr: Verordnung (EU) Nr. 181/2011 des Europäischen Parlaments und des Rates vom 16. Februar 2011 über die Fahrgastrechte im Kraftomnibusverkehr und zur Änderung der Verordnung (EG) Nr. 2006/2004, in Abl., 28. Februar 2011, L 55, S. 1 ff., ELI: http://data.europa.eu/eli/reg/2011/181/oj (21.08.2021). S. auch Europäischer Rechnungshof (Hrsg.), Die Fahr- und Fluggastrechte der EU sind umfassend, ihre Durchsetzung ist für die Reisenden jedoch nach wie vor schwierig, Sonderbericht Nr. 30, Luxemburg, 2018.

${ }^{92}$ Vgl. https://ec.europa.eu/commission/presscorner/detail/en/MEMO_19_1990 (21.08.2021).
} 
Wie bereits dargelegt, fußt die Gesetzgebungskompetenz der Union in diesem Bereich auf Art. 91 Abs. 1 lit. c AEUV. Auf dieser Grundlage wurde eine Vielzahl an Vorschriften erlassen, die unter anderem Kfz-Zulassungen, verschiedenartige Typengenehmigungen, schadstoffbezogene Emissionswerte, oder besondere Regelungen für den Transport von Gefahrgut ${ }^{93}$ betreffen. Auch die Gurtanlegepflicht in bestimmten Fahrzeugen wurde über eine Richtlinie geregelt. ${ }^{94}$

Die EU setzt auf Automatisierung, Digitalisierung und gemeinsam genutzte Mobilitätsdienste - Trends, die sich heute sicherlich rasch verbreiten - und unterstützt diese mit dem Ziel, den Verkehrssektor effizienter zu gestalten und damit die Verkehrssicherheit zu verbessern. ${ }^{95}$ Die Vereinheitlichung technischer Normen wurde auch in der Binnenschifffahrt ${ }^{96}$ und im Seerecht ${ }^{97}$ vorangetrieben. Bei der Luftfahrt wurden insbesondere Sicherheitsvorschriften vereinheitlicht, ${ }^{98}$ aber auch technische Vorschriften für den Flugbetrieb ${ }^{99}$ oder Regelungen für die durch Fluglärm legitimierten Betriebsbeschränkungen von Flughäfen. ${ }^{100}$

${ }^{93}$ Z. B. im Kontext von chemischen oder radioaktiven Stoffen: Richtlinie Nr. 2008/68/EG des Europäischen Parlaments und des Rates vom 24. September 2008 über die Beförderung gefährlicher Güter im Binnenland, in: Abl., 30. September 2008, L 260, S. 13 ff., ELI: http://data.europa. eu/eli/dir/2008/68/oj (21.08.2021).

${ }^{94}$ Richtlinie Nr. 2003/20/EG des Europäischen Parlaments und des Rates vom 8. April 2003 zur Änderung der Richtlinie Nr. 91/671/EWG des Rates zur Angleichung der Rechtsvorschriften der Mitgliedstaaten über die Gurtanlegepflicht in Kraftfahrzeugen mit einem Gewicht von weniger als 3,5 Tonnen, in: Abl., 9. Mai 2003, L 115, S. 63 ff., ELI: http://data.europa.eu/eli/dir/2003/20/oj (21.08.2021).

${ }^{95}$ Siehe Europäischer Rechnungshof (Hrsg.), Hin zu einem optimierten Verkehrssektor in der EU: Welche Herausforderungen gilt es zu bewältigen?, Landscape-Analyse, Luxemburg, 2018, S. 23.

${ }^{96}$ Richtlinie Nr. 2006/137/EC des Europäischen Parlaments und des Rates vom 18. Dezember 2006 zur Änderung der Richtlinie 2006/87/EG über die technischen Vorschriften für Binnenschiffe, in: Abl., 30. Dezember 2006, L 389, S. 261 ff., ELI: http://data.europa.eu/eli/dir/2006/137/ oj (21.08.2021).

${ }^{97}$ Z. B. Verordnung (EG) Nr. 336/2006 des Europäischen Parlaments und des Rates vom 15. Februar 2006 zur Umsetzung des Internationalen Codes für Maßnahmen zur Organisation eines sicheren Schiffsbetriebs innerhalb der Gemeinschaft und zur Aufhebung der Verordnung (EG) Nr. 3051/95 des Rates, in: Abl., 04. März 2006, L 61, S. 1 ff., ELI: http://data.europa.eu/eli/ reg/2006/336/oj (21.08.2021).

${ }^{98}$ Zuletzt etwa Richtlinie Nr. 2016/681/EU des Europäischen Parlaments und des Rates vom 27. April 2016 über die Verwendung von Fluggastdatensätzen (PNR-Daten) zur Verhütung, Aufdeckung, Ermittlung und Verfolgung von terroristischen Straftaten und schwerer Kriminalität, in: Abl., 4. Mai 2016, L 119, S. 132 ff., ELI: http://data.europa.eu/eli/dir/2016/681/oj (21.08.2021); allgemein zur Thematik etwa S. Keiler, Mut zur Lücke - die Fluggastrechte-VO zur Auslegung und Überprüfung vor dem EuGH, in: ZVR 2011, 228.

${ }^{99}$ Verordnung (EWG) Nr. 3922/91 des Rates vom 16. Dezember 1991 zur Harmonisierung der technischen Vorschriften und der Verwaltungsverfahren in der Zivilluftfahrt, in: Abl., 31. Dezember 1991, L 373, S. 4 ff., ELI: http://data.europa.eu/eli/reg/1991/3922/oj (21.08.2021).

${ }^{100}$ Z. B. Richtlinie 2002/30/EG des europäischen Parlaments und des Rates vom 26. März 2002 über Regeln und Verfahren für lärmbedingte Betriebsbeschränkungen auf Flughäfen der Gemeinschaft, in: Abl., 28. März 2002, L 85, S. 40 ff., ELI: http://data.europa.eu/eli/dir/2002/30/oj (21.08.2021). 


\subsection{Umwelt- und Klimaschutz}

Verschiedene Maßnahmen zur Rechtsangleichung finden sich zum Themenschwerpunkt Klima- und Umweltschutz. So wurde für den Bereich des Straßenverkehrs etwa der obligatorische Verkauf von bleifreiem Benzin und die Sicherung der Versorgung mit alternativen Kraftstoffen sekundärrechtlich geregelt. ${ }^{101} \mathrm{Im}$ Güterverkehr gewährt die Union verschiedene Finanzhilfen zur Verbesserung der Umweltfreundlichkeit. ${ }^{102}$

\subsection{Europäische Agenturen}

Für ausgewählte Verkehrsbereiche wurden entsprechende Agenturen geschaffen, die nicht nur die Verkehrssicherheit gewährleisten, die Sicherheit der Transporte vorantreiben und den jeweiligen Wettbewerb sichern und überwachen sollen, sondern auch auf die Vorbeugung von Unfällen abzielen.

Hierbei ist zunächst die Europäische Eisenbahnagentur (ERA) ${ }^{103,104}$ mit Sitz in Valenciennes und Lille (Nordfrankreich) zu nennen. ${ }^{105}$ Diese Agentur überwacht und fördert die Interoperabilität, die Wettbewerbsfähigkeit und die Sicherheit des europäischen Eisenbahnsystems. Insbesondere treibt die ERA auch alle Anstrengungen voran, um Signalvorschriften in allen EU-Mitgliedstaaten einzuführen. ${ }^{106}$

Als Folge der Havarie des Öltankers Erika vor der Küste der Bretagne im Jahr 1999 wurde 2002 die Europäische Agentur für die Sicherheit des Seeverkehrs (EMSA) $)^{107,108}$ gegründet, die sich der Verbesserung der Sicherheit auf See verschrieben hat und damit sowohl der Unfallprävention als auch dem Umweltschutz dient.

\footnotetext{
${ }^{101}$ Richtlinie Nr. 2014/94/EU des Europäischen Parlaments und des Rates vom 22. Oktober 2014 über den Aufbau der Infrastruktur für alternative Kraftstoffe, in: Abl., 28. Oktober 2014, L 307, S. 1, ELI: http://data.europa.eu/eli/dir/2014/94/oj (21.08.2021).

${ }^{102}$ Verordnung (EG) Nr. 1692/2006 des Europäischen Parlaments und des Rates vom 24. Oktober 2006 zur Aufstellung des zweiten Marco Polo-Programms über die Gewährung von Finanzhilfen der Gemeinschaft zur Verbesserung der Umweltfreundlichkeit des Güterverkehrssystems (Marco Polo II) und zur Aufhebung der Verordnung (EG) Nr. 1382/2003, in: Abl., 24. November 2006, L 328, S. 1 ff., ELI: http://data.europa.eu/eli/reg/2006/1692/oj (21.08.2021).

${ }^{103} \mathrm{ERA}=$ European Union Agency for Railways, kurz European Railways Agency.

${ }^{104}$ Siehe https://www.era.europa.eu/ (21.08.2021).

${ }^{105}$ Verordnung (EG) Nr. 881/2004 des Europäischen Parlaments und des Rates vom 29. April 2004 zur Errichtung einer Europäischen Eisenbahnagentur, in: Abl., 30. April 2004, L 164, S. 1 ff., ELI: http://data.europa.eu/eli/reg/2004/881/oj (21.08.2021).

${ }^{106} \mathrm{Vgl}$. A. Brandenberg, Entwicklungen in der Eisenbahnregulierung aus europäischer Sicht, in: EuZW, 2009, S. 359 ff.; K. Gstettenbauer, Die sogenannten „Eisenbahnpakete“ der Europäischen Union, in: ZVR, 2009, S. 504 ff.

${ }^{107}$ EMSA = European Maritime Safety Agency.

${ }^{108}$ Vgl. http://www.emsa.europa.eu/ (21.08.2021); siehe Verordnung (EG) Nr. 1406/2002 des Europäischen Parlaments und des Rates vom 27. Juni 2002 zur Errichtung einer Europäischen Agentur für die Sicherheit des Seeverkehrs, in: Abl., 5. August 2002, L 208, S. 1 ff., ELI: http:// data.europa.eu/eli/reg/2002/1406/oj (21.08.2021).
} 
Schließlich ist die 2002 errichtete Europäische Agentur für Flugsicherheit (EASA) ${ }^{109,110}$ mit Sitz in Köln zu nennen, die die Flugsicherheitsbehörde der Europäischen Union für die zivile Luftfahrt bildet. ${ }^{11} \mathrm{Zu}$ ihren Aufgaben gehört die Erstellung und Überwachung einheitlicher Sicherheits- und Umweltstandards.

\section{Internationale Beziehungen und Regelungen im Verkehrsbereich}

Die Welt des Verkehrs ist seit jeher von einer internationalen Dimension geprägt, deren Regelungen folglich nicht an den Grenzen eines Staates halt machen können. In den letzten Jahrzehnten hat die Globalisierung des Transportsektors eine starke Dynamik erfahren, die sich der Notwendigkeit einer Reglementierung nicht entziehen konnte. Für einen funktionierenden europäischen Binnenmarkt braucht es nicht nur einen grenzüberschreitenden Verkehr zwischen den EU-Mitgliedstaaten, sondern auch einen transkontinentalen Verkehr. Der globale Handel erfordert nämlich, dass die EU im Verkehrsbereich auf internationaler und interkontinentaler Ebene aktiv wird, um die Effizienz des eigenen Handels, aber auch aller für ihren Markt relevanten wirtschaftlichen Tätigkeiten, zu gewährleisten. Demnach ist nicht nur eine Präsenz der Union in internationalen Verkehrsorganisationen, sondern auch die Kompetenz zum Abschluss völkerrechtlicher Abkommen mit Drittstaaten erforderlich.

Wie bereits erwähnt, fällt die gemeinsame Verkehrspolitik in den Bereich der geteilten Zuständigkeiten der EU ${ }^{112}$ und trotz ihres Vorrechts bleiben die Staaten weiterhin in diesem Bereich gesetzgeberisch tätig. Die Union besitzt jedoch ausschließliche Zuständigkeit im Bereich der gemeinsamen Handelspolitik. ${ }^{113}$ Das bedeutet, dass der Verkehr in alle Verhandlungen im Handelssektor der EU einbezogen wird und zwar auf WHO-Ebene, genauso wie auf kontinentaler und bilateraler Ebene. ${ }^{114}$

\footnotetext{
${ }^{109} \mathrm{EASA}=$ European Union Aviation Safety Agency.

${ }^{110} \mathrm{Vgl}$. https://www.easa.europa.eu/ (21.08.2021).

${ }^{111}$ Vgl. Verordnung (EG) Nr. 216/2008 des Europäischen Parlaments und des Rates vom $20 \mathrm{Fe}-$ bruar 2008 zur Festlegung gemeinsamer Vorschriften für die Zivilluftfahrt und zur Errichtung einer Europäischen Agentur für Flugsicherheit, zur Aufhebung der Richtlinie 91/670/EWG des Rates, der Verordnung (EG) Nr. 1592/2002 und der Richtlinie 2004/36/EG, in: Abl., 19. März 2008, L 79, S. 1 ff., ELI: http://data.europa.eu/eli/reg/2008/216/oj (21.08.2021).

${ }^{112}$ Vgl. Art. 4 Abs. 2 lit. g) und h) AEUV.

${ }^{113}$ Vgl. Art. 3 Abs. 1 lit. e) AEUV.

${ }^{114} \mathrm{Vgl}$. Europäische Kommission (Hrsg.), Weißbuch „Fahrplan zu einem einheitlichen europäischen Verkehrsraum - Hin zu einem wettbewerbsorientierten und ressourcenschonenden Verkehrssystem“, KOM (2011) 144 endgültig vom 28.03.2011, S. 18 (3.4. Die externe Dimension).
} 
Der Abschluss von internationalen Abkommen durch die Union ist im fünften Teil, Titel V AEUV normiert. ${ }^{115}$ Art. 216 AEUV sieht vor, dass die Union mit einem oder mehreren Drittländern, oder einer oder mehreren internationalen Organisationen eine Übereinkunft treffen kann, wenn dies in den Verträgen vorgesehen ist, oder wenn der Abschluss einer Übereinkunft im Rahmen der Politik der Union entweder zur Verwirklichung eines der in den Verträgen festgesetzten Ziele erforderlich, oder in einem verbindlichen Rechtsakt der Union vorgesehen ist, oder gemeinsame Vorschriften beeinträchtigen oder deren Anwendungsbereich ändern könnte. Diese Übereinkünfte sind dann sowohl für die Institutionen der Union als auch für die Mitgliedstaaten bindend. ${ }^{116}$

Die Norm kodifiziert die sogenannte AETR-Doktrin, die vom EuGHs geprägt wurde, ${ }^{117}$ und unter bestimmten Umständen von der Existenz impliziter Kompetenzen der EU ausging, also von Zuständigkeiten, die der Union von den Mitgliedstaaten nicht ausdrücklich übertragen worden waren. Gemäß dieser Theorie impliziter Kompetenzen ergibt sich die externe Zuständigkeit der Union aus dem Vorhandensein einer expliziten Kompetenz auf interner Ebene. Da die Verträge der EU eine explizite Zuständigkeit in einem bestimmten Bereich, wie beispielsweise dem Verkehrswesen einräumen, muss die EU folglich eine ähnliche Zuständigkeit für den Abschluss von Abkommen mit Drittstaaten in demselben Bereich haben. ${ }^{118}$

\footnotetext{
${ }^{115}$ Vgl. K. J. Jorgensen/K. V. Laatikainen (Hrsg.), Routledge Handbook on the EU and International Institutions, Routledge, London, 2018; M.E. Bartoloni, Politica estera e azione esterna dell'Unione europea, Editoriale scientifica, Napoli, 2012; M. Gatti, European External Action Service: Promoting Coherence through Autonomy and Coordination (Studies in EU External Relations), Martinus Nijhoff, Leiden, 2016; A. Dashwood/M. Maresceau (Hrsg.), Law and Practice of EU External Relations: Salient Features of a Changing Landscape, Cambridge University Press, Cambridge, 2. Aufl. 2009; C. Hill/M. Smith/S. Vanhoonacker (Hrsg.), International Relations and the European Union, Oxford University Press, Oxford, 3. Aufl. 2017; T. Giegerich, What Kind of Global Actor will the Member States Permit the EU to Be?, in: ZEuS, 20, 4, 2017, S. $397 \mathrm{ff}$.

${ }^{116}$ Vgl. G. Gattinara, Art. 216 TFUE, in: C. Curti Gialdino (Hrsg.), Codice dell'Unione europea operativo - TUE e TFUE commentati articolo per articolo, Edizione Simone, Napoli, 2012, S. 1582.

${ }^{117}$ Vgl. EuGH, Urteil vom 31.03.1971, Rs. 22/70, Kommission der Europäischen Union gegen Rat der Europäischen Union, in: Sammlung der Rechtsprechung, 1971, S. 263 ff., ECLI:EU:C:1971:32; siehe auch EuGH, Gutachten 1/76 vom 26 April 1977, Entwurf zu einem Übereinkommen über die Errichtung eines europäischen Stilllegungsfonds für die Binnenschifffahrt, in: Sammlung der Rechtsprechung, 1977, S. 741, ECLI:EU:C:1977:63 und EuGH, Gutachten 1/94 vom 15. November 1994, Zuständigkeit der Gemeinschaft für den Abschluss völkerrechtlicher Abkommen auf dem Gebiet der Dienstleistungen und des Schutzes des geistigen Eigentums, in: Sammlung der Rechtsprechung, 1994, I, S. 5267 ff., ECLI:EU:C:1994:384.

${ }^{118}$ Vgl. https://eur-lex.europa.eu/summary/glossary/community_powers.html?locale=de (21.08.2021); siehe auch R. Adam/A. Tizzano, Manuale di diritto dell'Unione Europea, G. Giappichelli Editore, Torino, 2. Aufl. 2017, S. 825.
} 


\subsection{Landverkehr}

In diesem Zusammenhang nehmen die Europäische Kommission und der Rat an den Arbeiten der UN-Wirtschaftskommission für Europa (ECE) $)^{119}$ in Genf teil. Auf diesem Forum wurden verschiedene internationale Verkehrsabkommen geschlossen, so beispielsweise das AETR-Abkommen über die Arbeit des im internationalen Straßenverkehr beschäftigten Fahrpersonals. ${ }^{120}$

Den Status einer Beobachterin nimmt die Union hingegen in verschiedenen anderen Institutionen ein, etwa in der 1953 gegründeten Europäischen Konferenz der Verkehrsminister (CEMT), ${ }^{121}$ bei Verkehrsanliegen im Rahmen der Organisation für wirtschaftliche Zusammenarbeit und Entwicklung (OECD), ${ }^{122}$ welche 1961 ihre Tätigkeit aufnahm, im 1949 gegründeten Europarat, ${ }^{123}$ oder in der Zwischenstaatlichen Organisation für den internationalen Eisenbahnverkehrs (OTIF), ${ }^{124}$ welche 1985 mit Sitz in Bern (Schweiz) gegründet wurde und die Aufgaben der Union internationale des chemins de fer (UIC), ${ }^{125}$ die 1922 mit Sitz in Paris gegründet worden war, weiterführte sowie im Internationalen Eisenbahntransportkomitee (CIT). ${ }^{126}$

Eine besonders praktische Bedeutung haben die Verträge mit der Schweiz beim Alpentransit, also dem Alpen querenden Güterverkehr, der seit 1. Juni 2002 im Landverkehrsabkommen zwischen der EU und der Schweiz geregelt ist. ${ }^{127}$

\footnotetext{
${ }^{119}$ UNECE = United Nations Economic Commission for Europe. . Es handelt sich um eine der fünf regionalen Kommissionen, durch welche der Wirtschafts- und Sozialrat der Vereinten Nationen (ECOSOC = United Nations Economic and Social Council) tätig ist; siehe https://www.un.org/ ecosoc/en/ (21.08.2021).

${ }^{120} \mathrm{AETR}=$ Accord Européen sur les Transports Routiers; engl. European Agreement concerning the work of crews of vehicles engaged in international Road Transport.

${ }^{121} \mathrm{CEMT}=$ Conférence Européenne des Ministres des Transports; $\mathrm{ECMT}=$ European Conference of Ministers of Transport.

${ }^{122} \mathrm{OECD}=$ Organization for Economic Co-operation and Development; https://www.oecd.org (21.08.2021). Siehe in besonderer Weise das International Transport Forum (ITF) der OECD, siehe https://www.itf-oecd.org (21.08.2021).

${ }^{123} \mathrm{CoE}=$ Council of Europe; siehe https://www.coe.int/it/web/portal/home (21.08.2021).

${ }^{124} \mathrm{OTIF}=$ Organisation intergouvernementale pour les Transports Internationaux Ferroviaire, engl. Intergovernmental organisation for international carriage by rail; siehe http://otif.org/en/ (21.08.2021).

${ }^{125}$ Siehe https://uic.org (21.08.2021).

${ }^{126} \mathrm{CIT}=$ Comité International des Transports Ferroviaires; siehe https://www.cit-rail.org/de/ (21.08.2021).

${ }^{127}$ Abkommen zwischen der Europäischen Gemeinschaft und der Schweizerischen Eidgenossenschaft über den Güter- und Personenverkehr auf Schiene und Straße, in: Abl., 30 April 2002, L 114, S. 91 ff. Auf Schweizer Seite: Abkommen vom 21. Juni 1999 zwischen der Schweizerischen Eidgenossenschaft und der Europäischen Gemeinschaft über den Güter- und Personenverkehr auf Schiene und Straße, in: https://www.admin.ch/opc/de/official-compilation/2002/1649.pdf (21.08.2021).
} 
Auf materiellrechtlicher Ebene ist für alle EU-Mitgliedstaaten ${ }^{128}$ die Internationale Vereinbarung über Beförderungsverträge auf Straßen (CMR $)^{129}$ für den Transportbereich von zentraler Bedeutung. Dieser am 19. Mai 1956 in Genf unterschriebene und am 2. Juli 1961 in Kraft getretene wirtschaftsvölkerrechtliche Vertrag, schafft einheitliche Regeln für die entgeltliche Beförderung von Gütern auf der Straße mittels Fahrzeugen, meist Lastkraftwagen, wenn der Ort der Übernahme des Guts und der für die Ablieferung vorgesehene Ort, wie im Vertrag angegeben, in zwei verschiedenen Staaten liegen, von denen mindestens einer ein Vertragsstaat ist. Dies gilt ohne Rücksicht auf den Wohnsitz und die Staatsangehörigkeit der Parteien. ${ }^{130}$ Die CMR setzt die Existenz eines zivilrechtlich gültigen Beförderungsvertrags voraus und regelt dann bestimmte transportspezifische Aspekte wie beispielsweise den Frachtbrief, die Verantwortung und Haftung des Frachtführers. Alle Vorschriften der CMR, mit Ausnahme jener über das Innenverhältnis zwischen aufeinander folgenden Frachtführern, gelten zwingend. ${ }^{131}$

Für den internationalen Eisenbahnbereich ist ebenfalls für die EU-Mitgliedstaaten ${ }^{132}$ das Übereinkommen über den internationalen Eisenbahnver$k e h r(\mathrm{COTIF})^{133}$ einschlägig. ${ }^{134}$ Der am 9. Mai 1980 unterschriebene Vertrag ist heute in der Fassung des Änderungsprotokolls von Vilnius vom 3. Juni 1999 - in Kraft ab 1. Juli 2006 - rechtsverbindlich (COTIF 1999). Ziel dieses völkerwirtschaftsrechtlichen Vertrages ist die Festlegung einheitlicher Rechtsnormen für die Beförderung von Personen und Gütern im durchgehenden internationalen Eisenbahnverkehr, einschließlich ergänzender Beförderungen mit anderen Beförderungsmitteln, die Gegenstand eines einzigen Vertrages sind. Das COTIF aus dem Jahre 1999 hat sieben Anhänge. Die drei ersten davon dürfen hier hervorgehoben werden: Anhang A enthält einheitliche Rechtsvorschriften (ER) für den Vertag über die

\footnotetext{
${ }^{128}$ Der CMR sind bis heute 55 Staaten beigetreten, darunter alle wichtigen kontinentaleuropäischen Staaten und viele asiatische Staaten. Eine Liste dieser Staaten findet sich unter: https://unece.org/ transport/introduction-and-status (21.08.2021).

${ }^{129} \mathrm{CMR}=$ Convention relative au contrat de transport international de marchandises par route. Der Vertrag ist in englischer und französischer Sprache rechtsverbindlich. Siehe K.-H. Thume (Hrsg.), CMR - Kommentar. Übereinkommen über den Beförderungsvertrag im internationalen Straßengüterverkehr, Verlag Recht und Wirtschaft, Frankfurt, 3. Aufl. 2013; M. Paschke/W. Furnell, Transportrecht, C.H. Beck, München, 2011, S. 183 ff.; M. Zehetbauer/W. Motter, Nationales und Internationales Transportrecht: Straße, Schiene, Luft und Wasser, Verlag Österreich, Wien, 2017, S. $65 \mathrm{ff}$.

${ }^{130}$ Vgl. Art. 1 Abs. 1 CMR.

${ }^{131}$ Vgl. Art. 40, 41 CMR; siehe M. Zehetbauer/W. Motter, Nationales und Internationales Transportrecht: Straße, Schiene, Luft und Wasser, Verlag Österreich, Wien, 2017, S. 59 ff.

${ }^{132}$ Für die Liste aller 45 Mitgliedsstaaten, siehe http://otif.org/de/?page_id=51 (21.08.2021).

${ }^{133} \mathrm{COTIF}=$ Convention relative aux transports internationaux ferroviaires; engl. Convention con cerning International Carriage by Rail; vgl. W. Kunz, Eisenbahnrecht. Systematische Sammlung mit Kommentierungen der deutschen, europäischen und internationalen Vorschriften. Grundwerk mit 52. Ergänzungslieferung. Loseblattwerk, Nomos, Baden-Baden, 2019.

${ }^{134}$ Vgl. M. Paschke/W. Furnell, Transportrecht, C.H. Beck, München, 2011, S. 221 ff.; M. Zehetbauer/W. Motter, Nationales und Internationales Transportrecht: Straße, Schiene, Luft und Wasser, Verlag Österreich, Wien, 2017, S. 203 ff.
} 
internationale Eisenbahnbeförderung von Personen (CIV); Anhang B enthält einheitliche Rechtsvorschriften für den Vertrag über die internationale Eisenbahnbeförderung von Gütern (CIM); Anhang C enthält die Ordnung für die internationale Eisenbahnbeförderung gefährlicher Güter (RID). Der Anhang D befasst sich schließlich mit der Verwendung von Wagen (CUV), der Anhang E mit der Nutzung der Infrastruktur (CUI), Anhang F mit einheitlichen technischen Vorschriften (APTU) und Anhang G mit den technischen Vorschriften für die Zulassung von Eisenbahnmaterial (ATMF).

Die Europäische Union ist neben den Mitgliedstaaten dem COTIF mit Wirkung ab 1. Juli 2011 beigetreten. ${ }^{135}$

\subsection{Schifffahrt}

Im Bereich der Schifffahrt gilt es zwischen dem Transport von Gütern und Personen auf Binnenwasserstraßen, der in Europa im Allgemeinen auf Wasserläufen oder Seen stattfindet, und dem Transport von Gütern und Personen auf dem Seeweg zu unterscheiden, der weltweit stattfindet und in den letzten Jahrzehnten ein Ausmaß erreicht hat wie nie zuvor in der Geschichte der Menschheit. Die zunehmende Verbreitung des multimodalen Verkehrs ${ }^{136}$ lässt vermuten, dass der Seeverkehr auch in Zukunft weiter zunehmen wird und, hinsichtlich des Güterverkehrs, zumindest mittelfristig, das Feld nicht dem Luftverkehr überlassen wird.

Was den Transport von Gütern und Personen auf Binnenwasserstraßen betrifft, so hat der Unionsgesetzgeber eine ganze Reihe von Rechtsakten ${ }^{137}$ zur Regelung dieses Sektors erlassen. Insbesondere für die Binnenschifffahrt gibt es besondere Vorschriften, die sich aus internationalen Abkommen oder Verträgen der EU ergeben, wenn Wasserläufe in Nicht-EU-Staaten führen oder aus diesen kommen. In diesem Kontext ist auf die Revidierte Rheinschifffahrtsakte vom 17. Oktober 1868

\footnotetext{
${ }^{135}$ Die Union ist dem Übereinkommen über den internationalen Eisenbahnverkehr vom 9. Mai 1980, geändert durch das Protokoll von Vilnius vom 3. Juni 1999 (COTIF Übereinkommen), gemäß des Beschlusses Nr. 2013/103/EU des Rates vom 16. Juni 2011 über die Unterzeichnung und den Abschluss der Vereinbarung zwischen der Europäischen Union und der Zwischenstaatlichen Organisation für den internationalen Eisenbahnverkehr über den Beitritt der Europäischen Union zum Übereinkommen über den internationalen Eisenbahnverkehr (COTIF) vom 9. Mai 1980 in der Fassung des Änderungsprotokolls von Vilnius vom 3. Juni 1999, in: Abl., 23. Februar 2013, L 51, S. 1 ff., beigetreten.

${ }^{136}$ Siehe zum Thema Ch. Perathoner, Il trasporto multimodale nel diritto dell'Unione Europea: un fenomeno trasportistico emergente privo di un'adeguata regolamentazione, in diesem Band.

${ }^{137}$ Siehe dazu die Auflistung unter https://ec.europa.eu/transport/modes/inland_en (21.08.2021) unter dem Schlagwort „Compilation of EU legislation in the field of inland waterways“. Die Vorschriften umfassen die Verordnung (EG) Nr. 1356/96 des Rates vom 8. Juli 1996 über gemeinsame Regeln zur Verwirklichung der Dienstleistungsfreiheit im Binnenschiffsgüter- und -personenverkehr zwischen Mitgliedstaaten, in: Abl., 13 Juli 1996, L 175, S. 7 f., ELI: http://data.europa.eu/eli/ reg/1996/1356/oj (21.08.2021).
} 
(Mannheimer Akte) $)^{138}$ sowie auf das Übereinkommen über die Regelung der Schiffahrt auf der Donau vom 18. August 1948 (Belgrader Donaukonvention oder Akte $)^{139}$ zu verweisen. ${ }^{140}$

Aus materiellrechtlicher Sicht ist für die Binnenschifffahrt in Europa das Budapester Übereinkommen über den Vertrag über die Güterbeförderung in der Binnenschifffahrt $(\mathrm{CMNI})^{141}$ hervorzuheben. ${ }^{142}$ Nicht alle Mitgliedstaaten der EU sind dem Vertrag beigetreten, sondern nur jene, die eine ausgeprägte Binnenschifffahrt betreiben. ${ }^{143}$ Dieser völkerwirtschaftsrechtliche Vertrag wurde auf einer von der Zentralkommission für die Rheinschifffahrt (ZKR), ${ }^{144} \operatorname{der}$ Donaukommission ${ }^{145}$ und der Wirtschaftskommission für Europa der Vereinten Nationen (UNECE) ${ }^{146}$ ein-

\footnotetext{
${ }^{138}$ An der Mannheimer Rheinschifffahrtsakte ist neben den EU-Mitgliedstaaten Belgien, Deutschland, Frankreich und den Niederlanden auch der Drittstaat Schweiz beteiligt. Die heute gültige Version wurde am 20. November 1963 in Straßburg unterzeichnet und durch Zusatzprotokolle ergänzt (heute gültige Fassung ist vom 11. März 1969). Nach dem Grundsatz in Art. 351 Abs. 1 AEUV von den Regelungen der Art. 90 ff. AEUV ausgenommen, vgl. $R$. Bieber, in: R. Bieber/A. Epiney/M. Haag/M. Kotzur (Hrsg.), Die Europäische Union. Europarecht und Politik, Nomos, Baden-Baden, 12. Aufl. 2016, § 24 Rn. 20 ff.; E. Brandt, Verkehrspolitik und transeuropäische Netze, in: M. Röttinger/C. Weyringer (Hrsg.), Handbuch der europäischen Integration, Manz, Wien, 2. Aufl. 1996, S. 917 (921 f.); siehe in besonderer Weise auch: F. Meißner, Das Recht der Europäischen Wirtschaftsgemeinschaft im Verhältnis zur Rheinschifffahrtsakte von Mannheim. Ein Beitrag zur völkervertragsrechtlichen Bedeutung des Artikels 234 EWGV, Duncker \& Humblot, Berlin 1973.

${ }^{139}$ Vgl. Die Donaukommission, internationale Organisation der Donau-Anrainerstaaten mit Sitz in Budapest, verfolgt das staatenübergreifende Ziel die Donau-Schifffahrt zu organisieren und zu reglementieren; siehe: https://www.danubecommission.org/dc/de/ (21.08.2021); vgl. auch F. Pichler, Die Donaukommission und die Donaustaaten. Kooperation und Integration. (Schriftenreihe der Österreichischen Gesellschaft für Außenpolitik und Internationale Beziehungen, Band 8), Braumüller, Wien 1973.

${ }^{140}$ Zuvor war die Donau-Schifffahrt durch die Genfer Konvention vom 23. Juli 1921 und später durch ein am 18. August 1938 in Sinaia unterzeichnetes Abkommen geregelt worden; siehe dazu R. Mosca, Il regime internazionale del Danubio e la guerra e altri studi, Societas Carpato Dabuniana, Budapest, 1943. Art. 351, Abs. 1 AEUV findet auch völkerrechtliche Verträge, die von den EU-Mitgliedstaaten vor dem Gründungsjahr 1958 abgeschlossen wurden.

${ }^{141} \mathrm{CMNI}=$ Convention de Budapest relative au contract de transport de marchandises en navigation intérieure; engl. Budapest Convention on the Contract for the Carriage of Goods by Inland Waterways.

${ }^{142}$ Vgl. M. Paschke/W. Furnell, Transportrecht, C.H. Beck, München, 2011, S. 233 ff.; M. Zehetbauer/W. Motter, Nationales und Internationales Transportrecht: Straße, Schiene, Luft und Wasser, Verlag Österreich, Wien, 2017, S. 373 ff.

${ }^{143}$ Gegenwärtig ist der Vertrag in 16 Staaten in Kraft, darunter beispielsweise Deutschland, Frankreich und die BeNeLux-Staaten; eine Liste der Mitglieder findet sich https://www.unece.org/trans/ main/sc3/sc3_cmni_legalinst.html (21.08.2021).

${ }^{144}$ Franz. Commission Centrale pour la Navigation du Rhin (CCNR); niederl. Centrale Commissie voor de Rijnvaart (CCR); siehe https://www.ccr-zkr.org/ (21.08.2021).

${ }^{145}$ Siehe https://www.danubecommission.org/dc/de/ (21.08.2021).

${ }^{146}$ Engl. United Nations Economic Commission for Europe (UNECE od. UN/ECE od. ECE); siehe http://www.unece.org/info/ece-homepage.html (21.08.2021).
} 
berufenen diplomatischen Staatenkonferenz, die vom 25. September bis zum 3. Oktober 2000 in Budapest stattfand, ausgearbeitet, verabschiedet und am 20.-22. Juni 2001 von den meisten der heutigen Mitgliedstaaten unterzeichnet. Das Abkommen kommt dann zur Anwendung, wenn der Ladehafen bzw. Übernahmeort und der Löschhafen bzw. Ablieferungsort in zwei verschiedenen Staaten liegen und mindestens einer dieser Staaten Vertragsstaat des Abkommens ist. ${ }^{147}$

Von der Binnenschifffahrt ist der Seeverkehr auf den Weltmeeren zu unterscheiden. Neben verschiedenen Abkommen zum Seeverkehr, die mit Drittstaaten geschlossen wurden, schützt die Union die Schiffe der jeweiligen Mitgliedstaaten gegen allfällige Diskriminierungen durch Drittstaaten. Schließlich vertritt die Kommission die Unionsinteressen als Beobachterin bzw. als Vertreterin der Union in den verschiedenen internationalen Organisationen mit Schwerpunkt im Seerecht, wie etwa in der Internationalen Seeschifffahrts-Organisation (IMO), ${ }^{148}$ eine Sonderorganisation der Vereinten Nationen mit Sitz in London, in der Konferenz der Vereinten Nationen für Handel und Entwicklung (UNCTAD), ${ }^{149}$ in der Welthandelsorganisation (WTO), ${ }^{150}$ sowie in der bereits genannten Organisation für wirtschaftliche Zusammenarbeit und Entwicklung (OECD).

Aus materiellrechtlicher Sicht gibt es im Bereich des Seetransportrechts mehrere völkerwirtschaftsrechtliche Übereinkommen. Die besondere Komplexität einer einheitlichen Regulierung ergibt sich sicher auch daraus, dass die Seetransporte den interkontinentalen Warenaustausch heute regelrecht dominieren und somit auch die Interessen der verschiedenen Staaten, Staatenverbünde und Kontinente, auch aufgrund der unterschiedlichen Rechtskulturen und Rechtstraditionen, sehr unterschiedlich sein können.

Für den internationalen Seehandel wurden im Laufe der letzten hundert Jahre eine Reihe von völkerrechtlichen Verträgen geschlossen, um die materiellrechtlichen Verhältnisse im internationalen Transport einheitlich zu normieren. Einen wichtigen Meilenstein - vor allem für die Vereinheitlichung, Verwendung und Anerkennung von Konnossementen bzw. Frachtbriefen, die die zwingenden Mindesthaftungsregelungen des Seebeförderers gegenüber dem Verfrachter regeln, bildete das in Brüssel unterschriebene Übereinkommen vom 25. August 1924 zur Vereinheitlichung von Regeln über Konnossemente, das als Haager Regeln (HR $)^{151}$ bekannt ist. Die

\footnotetext{
${ }^{147}$ Vgl. Art. 2 CMNI.

${ }^{148} \mathrm{IMO}=$ International Maritime Organization. Diese IO verfolgt das Ziel der Förderung der technischen Entwicklung und Sicherheit des internationalen Seeverkehrs; siehe http://www.imo.org (21.08.2021).

${ }^{149} \mathrm{UNCTAD}=$ United Nations Conference on Trade and Development. Die Konferenz der Vereinten Nationen für Handel und Entwicklung ist ein Organ der Generalversammlung der Vereinten Nationen mit Sitz in Genf; siehe https://unctad.org (21.08.2021).

${ }^{150} \mathrm{WTO}=$ World Trade Organization . Die Welthandelsorganisation ist eine IO mit Sitz in Genf, die (gemeinsam mit Internationalen Währungsfonds und Weltbank) die Wirtschafts- und Handelspolitik global mitgestaltet; siehe https://www.wto.org (21.08.2021).

${ }^{151}$ Engl. International Convention for the Unification of Certain Rules of Law Relating to Bills of Lading oder Hague Rules.
} 
Initiative dieses Vertrages ist auf das Comité Maritime International (CMI $)^{152}$ zurückzuführen. Das CMI trieb in den Folgejahren die Anwendung des Vertrages voran, stellte im Laufe der Zeit jedoch einen Ergänzungs- und Reformbedarf der Regeln fest. Dies führte, ebenfalls in Brüssel, zur Unterfertigung des Protokolls vom 23. Februar 1968 zur Änderung des Übereinkommens vom 25. August 1924 zur Vereinheitlichung der Regeln von Konnossementen, das als Haag-Visby-Regeln (HVR) ${ }^{153}$ bekannt ist. Dieser neue, im Jahre 1977 in Kraft getretene Vertrag hat im Wesentlichen die Haftungsbeträge erhöht und die Haftung bei den Ladeeinheiten (Container, Pallets usw.) ergänzt. Am 21. Dezember 1979, immer in Brüssel, wurden die Haager Regeln mit einem 2. Protokoll, dem sogenannten SDR Protokoll 1979, ${ }^{154}$ ergänzt. Dieses Regelwerk erwies sich aber insgesamt als unzureichend und nicht mehr zeitgemäß. So wurde beispielsweise der aufstrebende multimodale Transport nicht bedacht. Infolgedessen wurde auf Initiative der Konferenz der Vereinten Nationen für Handel und Entwicklung (UNCTAD) ${ }^{155}$ und der Kommission der Vereinten Nationen für internationales Handelsrecht (UNCITRAL) ${ }^{156}$ auf einer Konferenz der Vereinten Nationen in Hamburg, an welcher Regierungsvertreter aus 78 Staaten teilnahmen, das UN-Übereinkommen vom 31. März 1978 über die Beförderung von Gütern auf See, auch bekannt als Hamburger Regeln, ${ }^{157}$ verabschiedet. Ziel der Konferenz war die Schaffung eines umfassenden Seefrachtrechts, das beispielsweise auch auf Seefrachtverträge anwendbar sein sollte, wenn kein Konnossement vorläge. Dieses Seefrachtrecht sollte sich allerdings nicht zu stark vom Landfrachtrecht differenzieren bzw. diesem sogar angenähert werden. So wurde auch eine stärkere Haftung des Verfrachters vorgesehen, was beispielsweise dazu führte, dass die Haftungsfreistellung für nautisches Verschulden abgeschafft wurde. Diese UN-Übereinkunft setzt sich ferner, erstmalig in der Seerechtsgeschichte, mit der Deck-Verlegung von Containern auseinander.

\footnotetext{
${ }^{152}$ Das CMI ist eine internationale Nichtregierungsorganisation (International Nongovernmental Organization, INGO). Es handelt sich um einen internationalen Verband, der im Jahre 1897 gegründet wurde, seinen Rechtssitz in Antwerpen hat und es sich zum Ziel macht, das internationale Seerecht zu vereinheitlichen. Vgl. L. Scott/C. Miller, The Unification of Maritime and Commercial Law through the Comité Maritime International, in: The International Law Quarterly, 1, 4 (Winter), 1947, S. 482 ff. Das CMI bereitete auch das Internationale Übereinkommen vom 23. September 1910 zur einheitlichen Feststellung bestimmter Regeln über den Zusammenstoß von Schiffen und das Internationale Übereinkommen vom 23. September 1910 zur einheitlichen Feststellung von Regeln über die Hilfeleistung und Bergung in Seenot vor und arbeitet aktiv bei der periodischen Überarbeitung der York-Antwerpener Regeln (YAR; York Antwerp Rules) mit.

${ }^{153}$ Engl. Protocol to Amend the International Convention for the Unification of Certain Rules of Law Relating to Bills of Lading, auch Hague-Visby Rules (HVR), oder nur Visby-Regeln (Visby Rules).

${ }^{154}$ Engl. Protocol (SDR Protocol) amending the International Convention for the Unification of Certain Rules of Law relating to Bills of Lading of 25 August 1924 (The Hague Rules), as amended by the Protocol of 23 February 1968 (Visby Rules).

${ }^{155} \mathrm{UNCTAD}=$ United Nations Conference on Trade and Development.

${ }^{156}$ UNCITRAL = United Nations Commission on International Trade Law.

${ }^{157}$ Engl. United Nations Convention on the Carriage of Goods by Sea (The Hamburg Rules).
} 
Im Bereich des multimodalen Transports wurden in den Folgejahren weitere Versuche einer Vereinheitlichung unternommen. Leider scheiterte das auf Betreiben der UNCTAD von 77 Staaten am 24. Mai 1980 verabschiedete Übereinkommen der Vereinten Nationen über den internationalen multimodalen Transport von Gütern (MTC) ${ }^{158}$ daran, dass die für das Inkrafttreten notwendigen 30 Unterschriften bei Weitem nicht erreicht wurden. Dabei wird der multimodale Transport für den europäischen und internationalen Handel immer wichtiger. Das Fehlen einer vereinheitlichten Reglementierung wirkt sich wiederum nachteilig auf grenzüberschreitende Wirtschaftsbeziehungen aus. Hier könnte das MTC ansetzen, das den Inhalt heute üblicher Beförderungsverträge in einigen Bereichen modifizieren und verschiedene internationale Beförderungsabkommen - zumindest zum Teil - verdrängen könnte.

Im Rahmen der UNCITRAL wurde aufgrund eines mehrjährigen Projekts, an dem auch das Comité Maritime International (CMI) mitwirkte, das Übereinkommen der Vereinten Nationen über Verträge über die internationale Beförderung von Gütern ganz oder teilweise auf See ${ }^{159}$ ausgearbeitet. Dieses wurde am 11. Dezember 2008 von der Generalversammlung der Vereinten Nationen verabschiedet. ${ }^{160}$ Bei der Zeichnungskonferenz am 23. Oktober 2009 in Rotterdam, weshalb das Übereinkommen auch als Rotterdam-Regeln (RR) ${ }^{161}$ bekannt wurde, unterzeichneten nur sechzehn Staaten das Übereinkommen. Diesen schlossen sich in der Folge einige mehr an. Bis heute haben allerdings nur fünf Staaten - unter den EU-Mitgliedstaaten nur Spanien - das Übereinkommen ratifiziert. Für ein Inkrafttreten ist allerdings die Ratifizierungen durch mindestens zwanzig Staaten erforderlich, ${ }^{162}$ weshalb das Übereinkommen bis heute nicht rechtsverbindlich ist. Staaten, die die Rotterdam Regeln annehmen, ratifizieren und diesem völkerwirtschaftsrechtlichen Vertrag formell beitreten, kündigen gleichzeitig andere Seerechtsübereinkommen, wie die Haager Regeln, die Haag-Visby Regeln, oder die Hamburg Regeln. ${ }^{163}$ Die Umsetzung der Rotterdam Regeln wäre jedochvor allem deshalb wichtig, weil sie einerseits auch Seefrachtverträge ohne Konnossement regeln, dann aber auch eine Regulierung all jener Multimodal-Transportverträge vorsehen, bei denen eine Teilstrecke über das Meer verläuft.

\footnotetext{
${ }^{158}$ Engl. United Nations Convention of International Multimodal Transport of Goods, kurz MTC = Multimodal Transport Convention.

${ }^{159}$ Engl. United Nations Convention on Contracts for the International Carriage of Goods Wholly or Partly by Sea.

${ }^{160} \mathrm{Vgl}$. A/RES/63/122.

${ }^{161}$ Engl. Rotterdam Rules (RR). Vgl. K. Ramming (Hrsg.), Die Rotterdam Regeln, in: Schriften des Deutschen Vereins für Internationales Seerecht, Heft 107, Storck Verlag, Hamburg, 2011.

${ }^{162}$ Vgl. Art. 94 RR.

${ }^{163} \mathrm{Vgl}$. Art. 89 RR.
} 


\subsection{Luftverkehr}

Da der Luftverkehr seinem Wesen nach über die Grenzen der Union hinweg auf eine weltweite Ausrichtung aufbaut, kommt der „Außendimension“ der EU-Luftverkehrspolitik eine wichtige Rolle zu.

Während alte multilaterale Abkommen - wie etwa das Abkommen über die internationale Zivilluftfahrt (Chicagoer Abkommen) vom 7. Dezember 1944 - im Sinne des Art. 351 AEUV zwischen den Vertragsstaaten weiter gelten, hat der EuGH aus Art. 216 i.V.m. Art. 100 Abs. 2 AEUV eine EU-Außenkompetenz im Luftverkehr abgeleitet, weshalb die Union auf diesem Gebiet neue Abkommen schließen kann.

Konsequenterweise - und unter Hinweis auf den Verstoß gegen die Niederlassungsfreiheit von Fluggesellschaften innerhalb der EU - hat der EuGH bilaterale Abkommen von sieben EU-Mitgliedstaaten mit den USA für nichtig erklärt. ${ }^{164} \mathrm{In}$ zwischen wurde ein (gemischtes) EU-USA-Luftverkehrsabkommen geschlossen. ${ }^{165}$

Von zentraler Wichtigkeit für den Binnenmarkt im engeren Sinne, wie auch für die Entwicklung des kontinentaleuropäischen Flugverkehrs im weiteren Sinne, ist die Entwicklung eines einheitlichen europäischen Luftraums (SES), ${ }^{166}$ der vor allem

\footnotetext{
${ }^{164}$ Siehe die Rechtssache „Open Skies“, u. a. EuGH, Urteil vom 5. November 2002, Rs. C-466/98, Kommission der Europäischen Gemeinschaften gegen Vereinigtes Königreich Großbritannien und Nordirland, in: Sammlung der Rechtsprechung, 2002, I, S. 9427 ff., ECLI:EU:C:2002:624 und EuGH, Urteil vom 5. November 2002, Rs. C-476/98, Kommission der Europäischen Gemeinschaften gegen Bundesrepublik Deutschland - „Open-skies“, in: Sammlung der Rechtsprechung, 2002, I, S. 9855 ff., ECLI:EU:C:2002:63.

${ }^{165}$ Vgl. Beschluss 2007/339/EG des Rates und der im Rat vereinigten Vertreter der Regierungen der Mitgliedstaaten der Europäischen Union vom 25. April 2007 über die Unterzeichnung und vorläufige Anwendung des Luftverkehrsabkommens zwischen der Europäischen Gemeinschaft und ihren Mitgliedstaaten einerseits sowie den Vereinigten Staaten von Amerika andererseits, in: Abl., 25. Mai 2007, L 134, S. 1 ff.
}

${ }^{166}$ SES = Single European Sky. Der EuGH hatte die Möglichkeit der Beteiligung der EU an einem kontinentaleuropäischen Übereinkommen zur Schaffung eines gemeinsamen europäischen Luftraumes im Rahmen eines Gutachtens geprüft; vgl. EuGH, Gutachten vom 18. April 2002, Nr. 1/2000: GELR-Übereinkommens, in: Sammlung der Rechtsprechung, 2002, I, S. 3493 ff., ECLI:EU:C:2002:231.

Das erste Paket gemeinsamer Anforderungen zur Schaffung des Einheitlichen europäischen Luftraumes wurde im Jahre 2004 durch eine Reihe von Maßnahmen verabschiedet (SES 1): Verordnung (EG) Nr. 594/2004 des Europäischen Parlaments und des Rates vom 10. März 2004 zur Festlegung des Rahmens für die Schaffung eines einheitlichen europäischen Luftraums (,,Rahmenverordnung“), in: Abl., 31. März 2004, L 96, S. 1 ff., ELI: http://data.europa.eu/eli/reg/2004/549/ oj (21.08.2021). Verordnung (EG) Nr. 550/2004 des Europäischen Parlaments und des Rates vom 10. März 2004 über die Erbringung von Flugsicherungsdiensten im einheitlichen europäischen Luftraum („Flugsicherungsdienste-Verordnung“), in: Abl., 31. März 2004, L 96, S. 10 ff., ELI: http://data.europa.eu/eli/reg/2004/550/oj (21.08.2021); Verordnung (EG) Nr. 551/2004 des Europäischen Parlaments und des Rates vom 10. März 2004 über die Ordnung und Nutzung des Luftraums im einheitlichen europäischen Luftraum („Luftraum-Verordnung“), in: Abl., 31. März 2004, L 96, S. 20 ff.; Verordnung (EG) Nr. 552/2004 des Europäischen Parlaments und des Rates vom 10. März 2004 über die Interoperabilität des europäischen Flugverkehrsmanagementnetzes („Interoperabilitäts-Verordnung“), in: Abl., 31. März 2004, L 96, S. 26 ff., ELI: http://data.europa. eu/eli/reg/2004/551/oj (21.08.2021). Dieser Regulierungsrahmen wurde im Jahre 2009 durch weitere Maßnahmen verbessert (SES 2): Verordnung (EG) Nr. 1070/2009 des Europäischen Parla- 
seit dem Jahr 1999 vorangetrieben wird. Ziel dieser Bestrebung ist es, die Effizienz des Flugverkehrsmanagements (ATM) ${ }^{167}$ wie auch der Flugsicherungsdienste (ANS) ${ }^{168}$ und Flugverkehrsdienste (ATS ${ }^{169}$ im Allgemeinen zu erhöhen, indem die Zersplitterung des europäischen Luftraumes abgebaut wird. Diese Initiative steht prinzipiell nicht nur den EU-Mitgliedstaaten, sondern allen europäischen Staaten zur Verfügung. ${ }^{170}$

In verschiedenen internationalen Luftfahrtorganisationen werden die Unionsinteressen durch die Kommission als Beobachterin neben den Mitgliedstaaten vertreten; wie etwa in der bereits genannten Internationalen Zivilluftfahrtorganisation $(\mathrm{ICAO})^{171}$ mit Sitz in Montreal. In diesem Zusammenhang ist ebenso die 1960 gegründete Europäische Organisation zur Sicherung der Luftfahrt (auch Eurocontrol) ${ }^{172}$ mit Hauptsitz in Brüssel zu nennen. Es handelt sich hierbei um eine internationale Organisation, die im Jahre 1960 für die Weiterentwicklung der Flugsicherung und Luftverkehrskontrolle in Europa gegründet wurde. Dieser internationalen Organisation gehören sämtliche europäische Staaten, mit Ausnahme von Russland und Weißrussland, an.

Aus materiellrechtlicher Sicht ist das Warschauer Abkommen über die Beförderung im internationalen Luftverkehr (Warschauer Abkommen) ${ }^{173} \mathrm{zu}$ nennen, das heute allerdings für viele Staaten, die dem Montrealer Übereinkommen beigetreten sind, überholt ist. ${ }^{174}$ Dieser wirtschaftsvölkerrechtliche Vertrag wurde am 12. Oktober 1929 in Warschau unterschrieben, ist am 13. Februar 1933 in Kraft getreten, und zielte auf die Vereinheitlichung der Bestimmungen über die Beförderung von Perso-

ments und des Rates vom 21. Oktober 2009 zur Änderung der Verordnungen (EG) Nr. 549/2004, (EG) Nr. 550/2004, (EG) Nr. 551/2004 und (EG) 552/2004 im Hinblick auf die Verbesserung der Leistung und Nachhaltigkeit des europäischen Luftverkehrssystems, in: Abl., 14. November 2009, L 300, S. 34 ff., ELI: http://data.europa.eu/eli/reg/2009/1070/oj (21.08.2021).

${ }^{167}$ ATM = Air Traffic Management . Die Aufgabe des ATM besteht darin, sicherzustellen, dass sich die Luftfahrzeuge in allen Betriebsphasen sicher und effizient bewegen, was nur durch leistungsstarke Flugverkehrsdienste, ein sicheres Luftraummanagement und eine klare Verkehrsflussregelung erwirkt werden kann.

${ }^{168}$ ANS= Air Navigation Services. . Darunter versteht man alle im Rahmen der Flugsicherung erbrachten Dienste. Darunter fallen Flugverkehrsdienste, Kommunikations-, Navigations- und Überwachungsdienste, Flugwetterdienste, Flugberatungsdienste, usw.

${ }^{169}$ ATS = Air Traffic Services. Darunter fallen die verschiedenen Fluginformationsdienste, Flugwarndienste, Flugverkehrsberatungsdienste, Flugverkehrskontrolldienste usw.

${ }^{170}$ Siehe http://www.europarl.europa.eu/factsheets/it/sheet/133/luftverkehr-einheitlicher-europaischer-luftraum (21.08.2021).

${ }^{171} \mathrm{ICAO}=$ International Civil Aviation Organization; siehe https://www.icao.int (21.08.2021).

${ }^{172}$ Engl. European Organisation for the Safety of Air Navigation; siehe https://www.eurocontrol. int (21.08.2021). Siehe auch das Zusammenarbeitsabkommen zwischen EU und ICAO: Beschluss Nr. 2011/530/EU des Rates vom 31. März 2011 über die Unterzeichnung im Namen der Union und die vorläufige Anwendung einer Kooperationsvereinbarung zwischen der Europäischen Union und der Internationalen Zivilluftfahrt-Organisation zur Schaffung eines Rahmens für die verstärkte Zusammenarbeit, in: Abl., 9. September 2011, L 232, S. 1 ff.

${ }^{173}$ Engl. Convention for the Unification of Certain Rules Relating to International Carriage by Air, auch Warsaw Convention 1929 oder Rules for international carriage by air.

${ }^{174}$ Vgl. M. Zehetbauer/W. Motter, Nationales und Internationales Transportrecht: Straße, Schiene, Luft und Wasser, Verlag Österreich, Wien, 2017, S. 263 ff. 
nen (Passagierbeförderung), wie auch von Gütern (Luftfrachtverkehr) im internationalen Luftverkehr, ab. Um Anwendung zu finden, musste der Luftbeförderungsvertrag von den Parteien vertraglich explizit vereinbart oder die Staaten, in denen der Abgangs- und der Zielflughafen liegen (beide!), dieses Abkommen ratifiziert haben. Das Abkommen wurde von 138 Staaten ratifiziert. Das Warschauer Abkommen wurde im Laufe der Jahre immer wieder ergänzt und abgeändert. ${ }^{175}$

Mit den Jahren wuchs die Kritik am Warschauer Übereinkommen jedoch, weil es durch die häufigen Änderungen keinen organischen Regelkorpus mehr darstellte und vielen Entwicklungen des Luftverkehrs nicht mehr angemessen Rechnung trug. Dies führte nach Jahren der Vorbereitung am 28. Mai 1999 in Montreal zur Unterfertigung des Übereinkommens zur Vereinheitlichung bestimmter Vorschriften über die Beförderung im internationalen Luftverkehr, das als Montrealer Übereinkommen (MÜ) ${ }^{176}$ bekannt ist. Auch dieser völkerwirtschaftsrechtliche Vertrag, der seit 4. November 2003 in Kraft getreten ist, regelt den Gütertransport ebenso wie die Personenbeförderung. Im Wesen setzt sich das Übereinkommen das Ziel, einer einheitlichen organischen und in sich harmonischen Regulierung der Haftung von Fluggesellschaften bzw. Luftfahrtunternehmen beim Eintritt von Schäden, die Reisende, Reisegepäck oder allgemeine Fracht und Güter während internationaler Flüge erleiden. Die Europäische Union hat das Übereinkommen von Montreal ausdrücklich genehmigt, ${ }^{177}$ sodass es Teil der Unionsrechtsordnung ist. ${ }^{178}$ Durch die Verordnung (EG) Nr. 889/2002 werden die Vorschriften des Übereinkommens von Montreal auf alle Flüge angewandt, die von Luftfahrtunternehmen der EU durchgeführt werden, unabhängig davon, ob es sich um Inlandsflüge oder internationale Flüge handelt. ${ }^{179}$ Weltweit haben 131 Staaten den Vertrag ratifiziert.

\footnotetext{
${ }^{175}$ Siehe z. B. Haager Protokoll von 1955, Montreal-Interim Agreement von 1966, vier Montrealer Protokolle von 1975. Alle Änderungen finden sich online: https://www.icao.int/secretariat/legal/ Lists/Current\%20lists\%20of\%20parties/AllItems.aspx (21.08.2021).

${ }^{176}$ Engl. Convention for the Unification of Certain Rules for International Carriage by Air, auch Montreal Convention 1999 oder Rules for International carriage by air. Siehe dazu F. Reuschle, Montrealer Übereinkommen. Kommentar, Verlag de Gruyter, Berlin-New York, 2. Aufl. 2011; K. Tonner, Die EU-Fluggastrechte-VO und das Montrealer Übereinkommen, in: Verbraucher und Recht, 2011, 6, S. $203 \mathrm{ff}$.

${ }^{177}$ Vgl. 2001/539/EG: Beschluss des Rates vom 5. April 2001 über den Abschluss des Übereinkommens zur Vereinheitlichung bestimmter Vorschriften über die Beförderung im internationalen Luftverkehr (Übereinkommen von Montreal) durch die Europäische Gemeinschaft, in: Abl., 18. Juli 2001, L 194, S. 38, ELI: http://data.europa.eu/eli/dec/2001/539/oj (21.08.2021).

${ }^{178}$ Siehe Übereinkommen zur Vereinheitlichung bestimmter Vorschriften über die Beförderung im internationalen Luftverkehr (Übereinkommen von Montreal), in: Abl., 18. Juli 2001, L 194, S. 39 ff., ELI: http://data.europa.eu/eli/convention/2001/539/oj (21.08.2021).

${ }^{179}$ Verordnung (EG) Nr. 889/2002 des Europäischen Parlaments und des Rates vom 13. Mai 2002 zur Änderung der Verordnung (EG) Nr. 2027/97 des Rates über die Haftung von Luftfahrtunternehmen bei Unfällen, in: Abl., 30. Mai 2002, L. 140, S. 2 ff., ELI: http://data.europa.eu/eli/ reg/2002/889/oj (21.08.2021). Im Jahr 1997 hatte die Europäische Gemeinschaft die Verordnung (EG) Nr. 2027/97 des Rates vom 9. Oktober 1997 über die Haftung von Luftfahrtunternehmen bei der Beförderung von Fluggästen und deren Gepäck im Luftverkehr, in: Abl., 17. Oktober 1997, L 285 verabschiedet, die Luftfahrtunternehmen der EU die unbegrenzte Haftung für Todesfälle oder Körperverletzungen von Reisenden auferlegte.
} 


\section{Transeuropäische Netze - TEN}

Der gegenwärtige Titel XVI, Dritter Teil AEUV enthält die primärrechtlichen Regeln der Transeuropäischen Netze (TEN). ${ }^{180}$ Der Titel wurde im Jahre 1992 mit dem Vertrag von Maastricht geschaffen. ${ }^{181}$ Durch den Begriff „transeuropäisch“ wird suggeriert, dass die von der Regelung betroffenen Netze grenzüberschreitende Bedeutung haben müssen, wobei der Ausbau der Funktionalität des Binnenmarktes sowie volkswirtschaftliche Auswirkungen im Fokus stehen. ${ }^{182}$

Die TEN im Bereich der Verkehrsinfrastrukturen werden auch TEN-V ${ }^{183}$ genannt und umfassen Verkehrsinfrastrukturen im engeren Sinn sowie Verkehrsmanagement-, Ortungs- und Navigationssysteme, wenngleich der Schwerpunkt bei Autobahnen und Eisenbahn-Hochgeschwindigkeitsstrecken liegt.

Die TEN im Verkehrssektor sind jedoch nicht die einzigen transeuropäischen Netze, die Gegenstand der Unionspolitik sind. Die Telekommunikationsinfrastruktur (eTEN) ${ }^{184}$ welche die digitale Versetzung und die dazugehörigen Dienste umfasst, fällt ebenso in den Bereich der TEN. Des Weiteren wird auch die Energieinfrastruktur (TEN-E oder TEN-Energy) ${ }^{185}$ erfasst, wobei hier der Fokus auf der europaweiten Verbindung von Gas- und Elektrizitätsleitungen liegt. Insofern soll

\footnotetext{
${ }^{180} \mathrm{TEN}=$ Trans-European Networks.

${ }^{181}$ Instruktiv R. Bieber, in: R. Bieber/A. Epiney/M. Haag/M. Kotzur (Hrsg.), Die Europäische Union. Europarecht und Politik, Nomos, Baden-Baden, 12. Aufl. 2016, § 24 Rn. 32 f.; E. Brandt, Verkehrspolitik und transeuropäische Netze, in: M. Röttinger/C. Weyringer (Hrsg.), Handbuch der europäischen Integration, Manz, Wien, 2. Aufl. 1996, S. 917 (932 ff.); N. Ehlotzky, Grundfreiheiten im Spannungsfeld von Verkehr und Nachhaltigkeit. Eine Analyse anhand des Verkehrsprotokolls der Alpenkonvention, Nomos, Baden-Baden, 2014, S. 80 ff.; M. Krajewski, Grundstrukturen des Rechts öffentlicher Dienstleistungen, Springer, Berlin-Heidelberg, 2011, S. 240 ff. m.w.N.; zur rechtshistorischen Entwicklung siehe G. Schulze, Die Rolle der Europäischen Union beim Aufbau transeuropäischer Netze, in: W. Zippel (Hrsg.), Transeuropäische Netze, Nomos, Baden-Baden, 1996, S. 29 (31 ff.); C.D. Classen, in: T. Oppermann/C.D. Classen/M. Nettesheim, Europarecht, C.H. Beck, München, 8. Aufl. 2018, § 26 Rn. 33 ff.; Th. Müller in diesem Band.

${ }^{182}$ Ausführlich bei W. Frenz, Handbuch Europarecht Band 6: Institutionen und Politiken, Springer, Berlin-Heidelberg, 2011, Rn. $4290 \mathrm{ff}$.

${ }^{183}$ TEN-T = Trans-European Transport Networks. Zu den transnationalen Verkehrsnetzen gehören: 1) Straßennetze; 2) Eisenbahnstrecken; 3) Fluss- und Binnenwasserstraßen; 4) Häfen; 5) „Meeresautobahnen“; 6) Flughäfen; 7) kombinierter Verkehr; 8) Informations- und Managementnetz im Transportwesen; 9) Flugverkehrsmanagementnetz durch das Programm SESAR (Single European Sky ATM Research), wobei ATM für Air Traffic Management steht. Allgemein zum Thema, siehe https://ec.europa.eu/transport/themes/infrastructure/ten-t_en (21.08.2021).

${ }^{184} \mathrm{eTEN}=$ Trans-European Telecommunications Networks.

${ }^{185}$ TEN-E od. TEN-Energy = Trans-European Networks for Energy. Siehe dazu Verordnung (EU) Nr. 347/2013 des Europäischen Parlaments und des Rates vom 17. April 2013 zu Leitlinien für die transeuropäische Energieinfrastruktur und zur Aufhebung der Entscheidung Nr. 1364/2006/EG und zur Änderung der Verordnungen (EG) Nr. 713/2009, (EG) Nr. 714/2009 und (EG) Nr. 715/2009, in: Abl., 25. April 2013, L 115, S. 39 ff., ELI: http://data.europa.eu/eli/reg/2013/347/oj (21.08.2021); vgl. L. Giesberts/A. Tiedge, Die Verordnung zu Leitlinien für die transeuropäische Energieinfrastruktur, in: NVwZ, 13, 2013, 836-841; L. Giesberts/A. Tiedge, Vorhaben von gemeinsamem Interesse nach der TEN-E-Verordnung, in: EurUP, 11, 3, 2013, S. 166 ff.
} 
mittels TEN der Verkehrsbinnenmarkt und der wirtschaftlich-soziale Zusammenhalt vorangetrieben werden. ${ }^{186}$

Die transeuropäischen Netze können als technische Struktur betrachtet werden, mittels welcher die Grundfreiheiten der Union an Dynamik, Evolution und Stabilität gewinnen. ${ }^{187}$

\subsection{Rechtliche Einordnung, Zielvorgaben und Finanzierung}

Die Verlagerung von Kompetenzen zum Auf- und Ausbau transeuropäischer Netze auf Unionsebene ist im engen Zusammenhang mit der Verwirklichung des Binnenmarkts zu sehen. Nur durch die Gewährleistung entsprechender technischer Mittel kann die rechtlich verankerte Freiheit der Unionsbürger angemessen verwirklicht werden. ${ }^{188}$ Vor diesem Hintergrund ist die Verankerung der TEN-Politik im Recht der Europäischen Union zu sehen, die gleichzeitig mehrere Überschneidungen zu anderen Unionsregelungen aufweist, etwa Umweltschutz, öffentliche Auftragsvergabe und Wettbewerbspolitik, aber auch zur Verkehrspolitik in Art. 90 ff. AEUV. ${ }^{189}$ Ferner dient die Unionskompetenz im TEN-Bereich auch als Rechtsgrundlage für sämtliche Unionsmaßnahmen zur Entwicklung und Errichtung des europäischen globalen Navigationssatellitensystems Galileo $^{190}$ sowie der Europäischen Erweiterung des geostationären Navigationssystems Egnos. ${ }^{191}$

\footnotetext{
${ }^{186}$ Vgl. M. Krajewski, Grundstrukturen des Rechts öffentlicher Dienstleistungen, Springer, Berlin-Heidelberg, 2011, S. 240 f.; in diesem Zusammenhang spricht Frenz, Handbuch Europarecht Band 6: Institutionen und Politiken, Springer, Berlin-Heidelberg, 2011, Rn. 4298 von einer doppelten Zielausrichtung der Art. $170 \mathrm{ff}$. AEUV.

${ }^{187}$ Vgl. W. Frenz, Handbuch Europarecht, Band. 6: Institutionen und Politiken, Springer, Berlin-Heidelberg, 2011, Rn. 1237.

${ }^{188}$ Ebenda, Rn. 4295.

${ }^{189}$ Ebenda, Rn. 4297; ebenso M. Krajewski, Grundstrukturen des Rechts öffentlicher Dienstleistungen, Springer, Berlin-Heidelberg, 2011, S. 231 f., mit Blick auf die Unionskompetenzen in der Verkehrspolitik.

${ }^{190}$ Das Galileo-Programm ist ein ziviles Satellitenpositionierungs- und Navigationssystem (GNSS = Global Navigation Satellite System), das auf Initiative der EU und der Europäischen Weltraumorganisation geschaffen wurde, um von dem von den Vereinigten Staaten kontrollierten GPS-System (NAVSTAR Global Positioning System = Navigation Satellite Timing And Ranging Global Positioning System) unabhängig zu werden. Im Jahr 2004 wurde die Europäische Agentur für globale Satellitennavigationssysteme (= The European GNSS Agency; GAS), oder Europäische GNSS-Agentur als eine Agentur der Europäischen Union mit Sitz in Prag seit 2012 gegründet; siehe https://www.gsa.europa.eu/ (21.08.2021).

${ }^{191}$ EGNOS = European Geostationary Navigation Overlay System (= Europäische Erweiterung des geostationären Navigationssystems). Das System wurde durch die Zusammenarbeit zwischen der Europäischen Weltraumorganisation, der Europäischen Kommission und EUROCONTROL geschaffen. Es handelt sich um ein System, das aus Bodenstationen besteht, die mit einem Netzwerk von Satelliten verbunden sind, um die Genauigkeit und Zuverlässigkeit der Daten des NAVSTAR-GPS-Systems zu verbessern, das auch für den Transportsektor, wie z. B. die Flug- oder See-
} 
Die primärrechtlichen Grundlagen der TEN finden sich dabei in den Artikeln 170 bis 172 AEUV.

Art. 170 Abs. 2 AEUV definiert zunächst die Ziele der EU-Netzpolitik als Förderung des Verbunds der nationalen Netze sowie des Zugangs zu diesen Netzen. Aus dem Wortlaut der Vorschrift ergibt sich, dass die Union zur Verwirklichung des Binnenmarktziels ${ }^{192}$ und der EU-Strukturpolitik ${ }^{193}$ zum Auf- und Ausbau transeuropäischer Netze in den Bereichen der Infrastruktur von Verkehr, der Telekommunikation und Energie beiträgt. Durch diese Unterstützung soll der Verkehrsbinnenmarkt und der wirtschaftlich-soziale Zusammenhalt zugunsten der Unionsbürger, der Wirtschaftsbeteiligten sowie der regionalen bzw. lokalen Gebietskörperschaften verwirklicht werden.

Es geht damit um die Verkoppelung, oder besser die „Interoperabilität“, der jeweiligen nationalen Verkehrs-, Telekommunikations- und Energienetze, die bisher noch nebeneinander bestehen und über die TEN-Politik der Union zu einem abgestimmten gesamteuropäischen Verbund hin entwickelt werden sollen. ${ }^{194}$ Die Zielvorgabe nimmt dabei besonderen Bezug auf die Randgebiete der Union, die mit zentraleren Gebieten verbunden werden sollen.

Über den Begriff „Förderung“ soll zum Ausdruck kommen, dass die TENMaßnahmen von einzelnen Mitgliedstaaten und allenfalls von privaten Unternehmen durchgeführt werden sollen, die Union hingegen lediglich finanzielle und planerische Unterstützung leistet. ${ }^{195}$ In diesem Sinne fällt die TEN-Politik unter die geteilte Zuständigkeit zwischen Union und Mitgliedstaaten ${ }^{196}$ und unterliegt entsprechend dem Subsidiaritätsprinzip. ${ }^{197}$

So gibt die Union nach Art. 171 AEUV Leitlinien zur Verwirklichung der TEN-Politik vor, die häufig mittels Verordnungen beschlossen werden und im Rahmen von Aktionen bzw. „übrigen Maßnahmen“ - und damit über das Spektrum von Verordnungen, Richtlinien und Beschlüssen - konkret ausgestaltet werden. Die jeweiligen, vom Projekt betroffenen Mitgliedstaaten, müssen die Maßnahmen genehmigen. ${ }^{198}$

Die finanzielle Mithilfe der Union zur Unterstützung der TEN-Politik ist subsidiär, sodass die jeweiligen Mitgliedstaaten die Hauptlast des finanziellen Aufwands tragen und die Mitfinanzierung der Union höchstens $50 \%$ beträgt. Die

\footnotetext{
fahrtnavigation für schwierige Routen, unentbehrlich geworden ist. Siehe dazu https://www.esa. int/Applications/Navigation/Galileo_and_EGNOS (21.08.2021).

${ }^{192}$ Vgl. Art. 26 AEUV.

${ }^{193}$ Vgl. Art. 174 AEUV.

${ }^{194}$ Zur Thematik G. Schulze, Die Rolle der Europäischen Union beim Aufbau transeuropäischer Netze, in: W. Zippel (Hrsg.), Transeuropäische Netze, Nomos, Baden-Baden, 1996, S. 29 (36 f.).

${ }^{195}$ Vgl. C.D. Classen, in: T. Oppermann/C.D. Classen/M. Nettesheim, Europarecht, C.H. Beck, München, 8. Aufl. 2018, § 26, Rn. 34.

${ }^{196}$ Vgl. Art. 4 Abs. 2 lit. h AEUV.

${ }^{197}$ Vgl. Art. 5 EUV.

${ }^{198}$ Vgl. Art. 172 Abs. 2 AEUV.
} 
Finanzierung der Union wird über Verordnungen ${ }^{199}$ festgelegt und kann entweder direkt über die Mittel des EU- Haushalts oder über Kohäsionsfonds bzw. andere Strukturfonds erfolgen. ${ }^{200}$ Daneben beteiligt sich die Europäische Investitionsbank $(E I B)^{201}$ im Rahmen ihres Auftrages zu einer ausgewogenen und reibungslosen Entwicklung des Binnenmarkts im Interesse der Union ${ }^{202}$ an der Finanzierung der TEN-Projekte. In diesem Zusammenhang wurde im Jahre 2007 die Exekutivagentur für Innovation und Netze (INEA) ${ }^{203}$ als EU-Behörde mit Sitz in Brüssel geschaffen. ${ }^{204}$

Konkrete Beispiele für die TEN-Politik sind etwa transnationale Großprojekte in der Verkehrsinfrastruktur, wie der Brennerbasistunnel, ${ }^{205}$ die Rhein-RhôneKanalverbindung, oder allgemeine Anschlussstücke zwischen nationalen Hochgeschwindigkeitsstrecken im Eisenbahnverkehr. ${ }^{206}$

Die Fertigstellung des sogenannten Core Network, also der TEN-VKernnetzkorridore, ist für das Jahr 2030 als Teil der Strategien der EU und der Mitgliedstaaten zur Verwirklichung des TEN-V geplant. Um eine koordinierte Umsetzung der TEN-V zwischen den Mitgliedstaaten zu gewährleisten, hat die EU neun sogenannte Korridore ${ }^{207}$ definiert. Sie bilden gleichsam das Gerüst und die Basisstruktur der Verkehrsadern auf unserem Kontinent. Sie werden durch das

\footnotetext{
${ }^{199}$ Für den Zeitraum 2015-2020 war ein Rahmen von 33 Milliarden Euro vorgesehen; vgl. Verordnung (EU) Nr. 1316/2013 des Europäischen Parlaments und des Rates vom 11. Dezember 2013 zur Schaffung der Fazilität „Connecting Europe“, zur Änderung der Verordnung (EU) Nr. 913/2010 und zur Aufhebung der Verordnungen (EG) Nr. 680/2007 und (EG) Nr. 67/2010, in: Abl., 20. Dezember 2013, L 348, S. 129 ff., ELI: http://data.europa.eu/eli/reg/2013/1316/oj (21.08.2021).

${ }^{200}$ Folgende EU-Finanzierungsprogramme zielen auf die Unterstützung und Förderung von TEN-T-Projekten ab: Connecting Europe Facility (CEF), European Fund for Strategic Investment (EFSI), Horizon 2020, wie auch die European Structural and Investment Funds (ESIFs) und unter diesen der Cohesion Fund (CF) und der European Regional Development Fund (ERDF); vgl. https://ec.europa.eu/transport/themes/infrastructure_en (21.08.2021).

${ }^{201}$ Siehe https://www.eib.org/de/index.htm (21.08.2021).

${ }^{202}$ Vgl. Art. 309 Abs. 1 AEUV.

${ }^{203}$ INEA = Innovation and Networks Executive Agency; siehe: https://ec.europa.eu/inea/ (21.08.2021); vgl. zudem Beschluss der Kommission vom 26. Oktober 2006 zur Einrichtung der Exekutivagentur für das transeuropäische Verkehrsnetz gemäß der Verordnung (EG) Nr. 58/2003 des Rates, in: Abl., 6. Februar 2007, L 32, S. 88 ff., ELI: http://data.europa.eu/eli/dec/2007/60(1)/ oj (21.08.2021).

${ }^{204}$ Zur Finanzierung der transeuropäischen Netze, siehe https://www.europarl.europa.eu/factsheets/de/sheet/136/die-finanzierung-der-transeuropaischen-netze (21.08.2021) und auch H. Ruyters, Finanzierung der transeuropäischen Netze, in: W. Purrer (Hrsg.), Internationales Symposium Brenner Basistunnel und Zulaufstrecken, Tagungsbeiträge 28. Februar 2008, Innsbruck University Press, Innsbruck, 2008, S. 9 ff.

${ }^{205}$ Siehe den Beitrag von Konrad Bergmeister in diesem Band.

${ }^{206}$ Vgl. C.D. Classen, in: T. Oppermann/C.D. Classen/M. Nettesheim, Europarecht, C.H. Beck, München, 8. Aufl. 2018, § 26 Rn. 35.

${ }^{207}$ Eine grafische Darstellung aller neun Korridore findet sich https://ec.europa.eu/transport/themes/infrastructure/ten-t_en (21.08.2021).
} 
Europäische Eisenbahnverkehrsleitsystem (ERTMS) ${ }^{208}$ und die Meeresautobahnen (MoS) ${ }^{209}$ ergänzt.

Gleichzeitig stellen die Art. 170-172 AEUV eine Querschnittskompetenz der Union zu anderen Sachpolitiken, wie der Verkehrspolitik, der Energiepolitik und der Telekommunikationspolitik, dar; sie berühren aber auch andere wichtige Bereiche, wie den freien Wettbewerb, den Umweltschutz usw. Die Bestimmungen sind methodisch jedoch als Spezialvorschriften zu anderen vorrangigen EU-Sachpolitiken zu verstehen. Somit haben sie keine ausschließliche, sondern eine ergänzende Funktion zur EU-Verkehrspolitik. ${ }^{210}$

\subsection{Der Brennerbasis-Tunnel als Beispiel der Umsetzung der TEN-V-Politik der EU}

Gemeinhin definiert die grundlegende Verordnung (EU) Nr. 1315/2013 die Leitlinien für den Verkehrsbereich zur Verwirklichung eines umfassenden transeuropäischen Verkehrsnetzes im Land-, See- und Luftverkehr mit Entwicklungsperspektive bis $2050 .{ }^{211}$ Weitere spezifische Regelungen haben die Leitlinien näher konkretisiert, etwa zu den Sicherheitsanforderungen bei Straßentunneln. ${ }^{212}$

Bereits im Jahr 1994 hat der Europäische Rat vierzehn Projekte als vorrangige spezifische Vorhaben definiert, auf die sich die Mitfinanzierung durch die Union besonders konzentrieren sollte. Unter diesen Projekten befindet sich auch der in Bau befindliche Brennerbasistunnel (BBT) ${ }^{213}$ zwischen Innsbruck (A) und Franzensfeste

\footnotetext{
${ }^{208}$ ERTMS = European Rail Traffic Management System; siehe https://ec.europa.eu/transport/themes/infrastructure/european-rail-traffic-management-system_en (21.08.2021).

${ }^{209} \mathrm{MoS}=$ Motorways of the Sea ; siehe https://ec.europa.eu/transport/themes/infrastructure/motorways-sea_en (21.08.2021).

${ }^{210} \mathrm{Vgl}$. C.D. Classen, in: T. Oppermann/C.D. Classen/M. Nettesheim, Europarecht, C.H. Beck, München, 8. Aufl. 2018, § 26 Rn. 37.

${ }^{211}$ Verordnung (EU) Nr. 1315/2013 des Europäischen Parlaments und des Rates vom 11. Dezember 2013 über Leitlinien der Union für den Aufbau eines transeuropäischen Verkehrsnetzes und zur Aufhebung des Beschlusses Nr. 661/2010/EU, in: Abl., 20. Dezember 2013, L 348, S. 1 ff., ELI: http://data.europa.eu/eli/reg/2013/1315/oj (21.08.2021); siehe auch Verordnung (EU) Nr. 1316/2013 des Europäischen Parlaments und des Rates vom 11. Dezember 2013 zur Schaffung der Fazilität „Connecting Europe“, zur Änderung der Verordnung (EU) Nr. 913/2010 und zur Aufhebung der Verordnungen (EG) Nr. 680/2007 und (EG) Nr. 67/2010, in: Abl., 20. Dezember 2013, L 348, S. 129 ff., ELI: http://data.europa.eu/eli/reg/2013/1316/oj (21.08.2021). Vgl. dazu $R$. Bieber/F. Maiani, Europäisches Verkehrsrecht. Die Rechtspraxis sämtlicher Verkehrsträger, Nomos, Baden-Baden, 2015, S. $300 \mathrm{ff}$.

${ }^{212}$ Richtlinie 2004/54/EG des Europäischen Parlaments und des Rates vom 29. April 2004 über Mindestanforderungen an die Sicherheit von Tunneln im transeuropäischen Straßennetz, in: Abl., 30. April 2004, L 167, S. 39 ff., ELI: http://data.europa.eu/eli/dir/2004/54/oj (21.08.2021).

${ }^{213}$ Ital. Galleria di Base del Brennero; vgl. https://www.bbt-se.com und https://www.bbtinfo.eu/ brenner-basistunnel (21.08.2021).
} 
(I). Der Bau begann im Sommer des Jahres $2007^{214}$ und ist heute wohl das größte Verkehrsinfrastrukturprojekt zur Verbindung Deutschlands, Österreichs und Italiens. Der BBT bettet sich in die Eisenbahnachse Berlin-Palermo des SkandinavischMediterranen EU-Kernkorridors ${ }^{215}$ des TEN-V-Programms ein. Konkret handelt es sich um einen $55 \mathrm{~km}^{216}$ langen Eisenbahntunnel für den Personen- und Güterverkehr unter dem Brenner-Pass am Alpenhauptkamm. Obwohl sich die Verwirklichung dieser im Jahre 1994 als prioritär definierten Projekte insgesamt gesehen eher schleppend vollzog, gilt der Brennerbasistunnel als gemeinsames Projekt der Mitgliedstaaten Österreich und Italien ${ }^{217}$ trotz kleinerer Startprobleme und wiederholter Verzögerungen als Erfolgsmodell der TEN-V-Politik der Union. ${ }^{218}$

\section{Ausblick}

Aus Gründen, die heute nur noch schwer nachvollziehbar sind, blieb die Europäische Union Jahrzehnte nach ihrer Gründung im Verkehrsbereich untätig. Dabei wäre die gemeinsame Verkehrspolitik für die konkrete Verwirklichung der vier Grundfreiheiten von Anfang an unabdingbar gewesen. Ein Eingreifen des Gerichtshofs der Europäischen Union in den achtziger Jahren war also notwendig, ${ }^{219}$ um der Union den nötigen Impuls und Handlungsauftrag zu erteilen. Heute kann dieser Sektor als echte Triebkraft der Integration angesehen werden, wiewohl in vielen Bereichen noch ein akuter Handlungsbereich besteht.

\footnotetext{
${ }^{214}$ Für eine Analyse der Pro- und Contra-Argumente unmittelbar vor dem Beginn des Baues des Großprojektes BBT, siehe J. Kußtatscher (Hrsg.), Tunnelblick. Der Brennerbasistunnel. Fakten Argumente - Meinungen, Studien Verlag, Innsbruck, 2007.

${ }^{215}$ Siehe dazu https://ec.europa.eu/transport/themes/infrastructure/scandinavian-mediterranean_en (21.08.2021).

${ }^{216}$ Wenn die unterirdische Umfahrung der Stadt Innsbruck (A) miteingerechnet wird, hat der BBT eine Gesamtlänge von $64 \mathrm{~km}$.

${ }^{217}$ Zur Verwirklichung des BBT gründeten Österreich und Italien im Jahre 1999 zuerst eine Europäische Wirtschaftliche Interessenvereinigung (EWIV) BBT EWIV. Aus dieser ging am 16. Dezember 2004 die heute tätige Projektgesellschaft Galleria di Base del Brennero - Brenner Basistunnel BBT SE hervor. Letztere hat die Rechtsform einer Societas Europaea (SE) im Sinne Verordnung (EG) Nr. 2157/2001 des Rates vom 8. Oktober 2001 über das Statut der Europäischen Gesellschaft (SE), in: Abl., 10. November 2001, L 294 S. 1 ff., ELI: http://data.europa.eu/eli/ reg/2001/2157/oj (21.08.2021). Gesellschafter sind auf österreichischer Seite mit $50 \%$ der Gesellschaftsanteile die ÖBB Infrastruktur $A G$ und auf italienischer Seite die Tunnel Ferroviário del Brennero - società di Partecipazioni SpA. In Letzterer ist die Tochtergesellschaft der italienischen Staatsbahnen Rete Ferroviário Italiana SpA. mit rund 89 \% der Anteile dominierend, Minderheitenbeteiligungen gehören der Autonomen Provinz Bozen-Südtirol, der Autonomen Provinz Trient und der Provinz Verona.

${ }^{218}$ Konrad Bergmeister in diesem Band; siehe auch K. Bergmeister, Brenner Basistunnel - Brenner Base Tunnel - Galleria di Base del Brennero, Tappeiner, Bozen-Innsbruck, 2011.

${ }^{219}$ Vgl. EuGH, Urteil v. 22. Mai 1985, Rs. 13/83, Europäisches Parlament/Rat der Europäischen Union, in: Sammlung der Rechtsprechung, S. 1513 ff., ECLI:EU:C:1985:220.
} 
Verkehr und Mobilität sind nicht nur Gegenstand der europäischen Integration, sondern stellen auch ein Instrument dar, ohne das weder der Personen- und Warenverkehr in Europa noch der transkontinentale Handel denkbar wäre. Daraus könnte man schließen, dass der Verkehrssektor aufgrund der Schaffung eines Raums ohne Binnengrenzen zu den unionsrechtlich am stärksten liberalisierten Bereichen zählt. Dies ist aber nicht oder nur teilweise der Fall. Die Liberalisierung der Verkehrsmärkte ist im Zuge des allgemeinen Binnenmarktprozesses seit Mitte der 1980erJahre zwar in wichtigen Teilen erreicht worden. Schwachpunkte bei der Liberalisierung liegen jedoch weiterhin im Schienen- und Personennahverkehr und somit in zwei Bereichen von grundlegender wirtschaftlicher und sozialer Bedeutung. ${ }^{220}$

Der Schienenverkehr ist - nicht zuletzt, weil die Erbringung von Verkehrsleistungen ohne geeignete Schieneninfrastruktur unmöglich ist - in vielen Mitgliedstaaten noch immer fest in den Händen großer staatlicher und öffentlicher Unternehmen. Diese Körperschaften waren seit jeher eng mit der Spitze der öffentlichen Verwaltungen und auch mit politischer Macht verbunden. Dies hat in der Vergangenheit zu einer Ad-hoc-Gesetzgebung im Interesse der staatlichen Eisenbahnen geführt. Bislang gelang es nur wenigen privaten Unternehmen, erfolgreich in den Eisenbahnmarkt einzusteigen. Daran ändert auch der Umstand nichts, dass der Unionsgesetzgeber aus wettbewerbsrechtlichen Gründen eine Trennung des kostspieligen Eisenbahninfrastrukturbetriebs von der eigentlichen Erbringung von Verkehrsleistungen fordert. Es liegt daher an den einzelnen Mitgliedstaaten, die Gesamtverantwortung für die Entwicklung einer angemessenen Schieneninfrastruktur zu übernehmen. ${ }^{221}$ Erschwert werden entsprechende Bestrebungen insbesondere auch durch den schlechten Zustand des Schienennetzes einiger Mitgliedstaaten. ${ }^{222}$

Eine große Herausforderung der Zukunft wird auch der Schienengüterverkehr innerhalb der EU bleiben. Obwohl die Politik darauf hinarbeitet, dass Güter künftig nur mehr oder zumindest verstärkt auf Schienen und nicht mehr auf Straßen transportiert werden, sieht die Realität (noch) anders aus. In den letzten Jahrzehnten hat der Schienengüterverkehr trotz des Tätigwerdens des Unionsgesetzgebers - man denke an die Verabschiedung der vier „Eisenbahnpakete“ zwischen 2001 und 2016 - nicht wirksam auf die Wettbewerbsfähigkeit des Straßenverkehrs reagiert. Ein erster Grund hierfür liegt in der Fragmentierung des europäischen Eisenbahnmarktes. In vielen Mitgliedstaaten ist die Eisenbahninfrastruktur weiterhin veraltet oder anderweitig ungeeignet für die Bedürfnisse des europäischen Binnenmarktes, verbunden mit der geringen Geschwindigkeit der Züge, denn auf einigen

\footnotetext{
${ }^{220}$ Vgl. C.D. Classen, in T. Oppermann/C.D. Classen/M. Nettesheim, Europarecht, C.H. Beck, München, 8. Aufl. 2018, § 26, Rn. 41.

${ }^{221}$ Vgl. Richtlinie Nr. 2012/34/EU des Europäischen Parlaments und des Rates vom 21. November 2012 zur Schaffung eines einheitlichen europäischen Eisenbahnraums, in: Abl., 14. Dezember 2012, L 343, S. 32 ff., ELI: http://data.europa.eu/eli/dir/2012/34/oj (21.08.2021).

${ }^{222} \mathrm{Vgl}$. Europäischer Rechnungshof (Hrsg.), Der Schienengüterverkehr in der EU: noch nicht auf dem richtigen Kurs, Sonderbericht Nr. 8, Luxemburg, 2016, S. 27.
} 
internationalen Strecken fahren Güterzüge mit einer Durchschnittsgeschwindigkeit von nur $18 \mathrm{~km} / \mathrm{h} .^{223}$

Einen weiteren kritischen Aspekt stellen die administrativen wie auch die technischen Hemmnisse dar, welche die Wettbewerbsfähigkeit des Schienengüterverkehrs in Europa weiterhin einschränken. Hierzu zählen die langwierigen Verwaltungsverfahren, die für die Zulassung von Fahrzeugen und die Ausstellung von Sicherheitsbescheinigungen an Eisenbahnunternehmen erforderlich sind. Aus technischer Sicht können hingegen Einschränkungen der Interoperabilität festgestellt werden, wie beispielsweise unterschiedliche Signalsysteme zwischen den einzelnen Mitgliedstaaten. Nicht alle Mitgliedstaaten verwenden darüber hinaus die gleichen Elektrifizierungssysteme. ${ }^{224}$ Die Mitgliedstaaten sind nicht einheitlich in der zulässigen Höchstlänge für Züge ${ }^{225}$ und wenden unterschiedliche Achslastkategorien an. Schließlich fehlt in der EU eine gemeinsame Normalspurweite. ${ }^{226}$

Auch die Erbringung von Personenverkehrsdiensten mit Bus oder Straßenbahn als Teil des öffentlichen Nahverkehrs (ÖPNV) in Europa liegt hauptsächlich in der Hand öffentlicher Unternehmen, obwohl das Interesse privater Unternehmen am Markteintritt in diesem Bereich immer stärker wahrgenommen werden kann. Es handelt sich jedoch um einen regulierten Markt, auf dem das Streckennetz von den öffentlichen Verwaltungen festgelegt wird. Der EU-Gesetzgeber setzt klar darauf, dass in diesem Sektor die Vergabe öffentlicher Dienstleistungsaufträge durch öffentliche Ausschreibungen ${ }^{227}$ erfolgt, in der Erwartung, dass durch einen fairen Wettbewerb den Nutzern ein effizienterer Dienst, besserer Komfort und kundenorientierterer Service geboten werden kann. Die Verbesserung und Effizienzsteigerung der Dienstleistungen muss auch anhand strenger Beihilfenkontrollen erreicht werden. Diese tragen dazu bei, dass der öffentliche Versorgungsauftrag stärker mittels marktkonformer Mechanismen wahrgenommen wird.

Es stellt sich die Frage, ob eine Revision der Verträge bzw. des primären Unionsrechts hinsichtlich der gemeinsamen Verkehrspolitik notwendig geworden ist. Tatsächlich ist die gegenwärtige Normierung in Titel VI im dritten Teil des AEUV (Artikel 90-100) vielfach Gegenstand von Kritik. Immer wieder wird darauf verwiesen, dass die darin enthaltenen Regelungen in ihrer Gesamtheit unzureichend,

\footnotetext{
${ }^{223} \mathrm{Vgl}$. ebenda, S. 24 ff.

${ }^{224}$ Zum Beispiel: in Italien, Spanien und Polen werden $3 \mathrm{Kv}$ Gleichstrom-Eisenbahnstrecken betrieben. In Österreich, Deutschland und der Schweiz werden $15 \mathrm{Kv}$ Wechselstrom-Eisenbahnstrecken betrieben. Länder wie Frankreich oder die Tschechische Republik verwenden unterschiedliche Elektrifizierungssysteme innerhalb ihres Landes.

${ }^{225}$ Zum Beispiel: in Spanien beträgt die maximale Länge der Züge $450 \mathrm{~m}$, während sie im benachbarten Frankreich 740 m beträgt.

${ }^{226} \mathrm{Vgl}$. Europäischer Rechnungshof (Hrsg.), Der Schienengüterverkehr in der EU: noch nicht auf dem richtigen Kurs, Sonderbericht Nr. 8, Luxemburg, 2016, S. 41 f. Siehe auch Marco Kampp in diesem Band.

${ }^{227}$ Vgl. Verordnung (EG) Nr. 1370/2007 des Europäischen Parlaments und des Rates vom 23. Oktober 2007 über öffentliche Personenverkehrsdienste auf Schiene und Straße und zur Aufhebung der Verordnungen (EWG) Nr. 1191/69 und (EWG) Nr. 1107/70 des Rates, in Abl., 3. Dezember 2007, L 315, S. 1-13, ELI: http://data.europa.eu/eli/reg/2007/1370/oj (21.08.2021).
} 
unstrukturiert und ohne klaren Leitfaden $\operatorname{seien}^{228}$ bzw. die Definition der Ziele jene Bestimmtheit vermissen ließe, die für eine der wichtigsten Politiken der Union notwendig oder zumindest angebracht wäre. ${ }^{229}$ Dazu kommt, dass die Bestimmungen in den Artikeln 94, 97 und sogar 98 AEUV mittlerweile obsolet geworden sind.

Eine Revision des EU-Primärrechts wäre auch hinsichtlich der Neudefinierung der Kompetenzen der Union im Verkehrssektor erforderlich. Im Bereich der gemeinsamen Verkehrspolitik besitzt die EU geteilte Zuständigkeit, ${ }^{230}$ während die Handelspolitik in die ausschließliche Zuständigkeit der Union fällt. Da Handel und Transport Hand in Hand gehen, kann das immer wieder zu einer problematischen Asymmetrie führen. Es wäre deshalb sicher ratsam, auch die Verkehrspolitik zu den ausschließlichen Kompetenzen der Union zu erheben. Die ausschließliche Zuständigkeit der EU wäre sowohl in interner als auch externer Hinsicht vorteilhaft. Intern würde es die Beseitigung all jener Unterschiede zwischen den Mitgliedstaaten erleichtern, die den grenzüberschreitenden Verkehr weniger effizient machen, angefangen bei banalen Beispielen, wie der Vereinheitlichung der Eisenbahnbeschilderung in der EU oder der Einführung eines europäischen Eisenbahnführerscheins. Nach außen hin könnte die EU als eine politische Einheit agieren, so wie es etwa die großen Akteure auf dem globalen Markt, also die Vereinigten Staaten oder China, machen. Nur so ist es einem Staat wie China möglich, eine Verkehrsinfrastruktur wie die Neue Seidenstraße zu errichten. ${ }^{231}$

Die Europäische Union hat als wichtiger Akteur des Welthandels in Zukunft keine andere Wahl, als in der globalen Verkehrspolitik als Einheit zu handeln. Nur so können in internationalen Organisationen, wie der WHO, ZKR, Eurocontrol, IMO, ICAO, COTIF die Interessen Europas gewahrt und gestärkt werden. Des Weiteren wird die Öffnung der Märkte von Drittländern für Transportdienstleistungen, Produkte und Investitionen zu den Prioritäten der EU zählen müssen. Die Verkehrsdimension ist daher Thema aller Verhandlungen der Europäischen Union im Handelsbereich, d. h. konkret auf Ebene der WHO, wie auch regional und bilateral. ${ }^{232}$

Die Union wird auch Anstrengungen unternehmen müssen, um einen gemeinsamen europäischen Luftverkehrsraum zu schaffen, der etwa 60 Länder und eine Milliarde Einwohner umfassen wird. Zu diesem Zweck müssen mit den

\footnotetext{
${ }^{228}$ Siehe $R$. Adam/A. Tizzano, Manuale di diritto dell'Unione Europea, G. Giappichelli Editore, Turin, 2. Aufl. 2017, S. 586 f.

${ }^{229}$ Vgl. R. Bieber/F. Maiani, Europäisches Verkehrsrecht. Die Rechtspraxis sämtlicher Verkehrsträger, Nomos, Baden-Baden, 2015, S. 43.

${ }^{230}$ Vgl. Art. 4 Abs. 2 lit. g) e h) AEUV.

${ }^{231}$ Obor = One Belt, One Road; siehe A. Breinbauer, The Chinese Belt and Road Initiative and Its Implications for Europe, in: A. Breinbauer/L. Brennan/J. Jäger/A.G.M. Nachbagauer/A. Nölke (Hrsg.), Emerging Market Multinationals and Europe. Challenges and Strategies, Springer, Cham, 2019, 213 ff.; P. Frankopan, The New Silk Roads. The Present and Future of the World, Bloomsbury Publishing, London, 2018; N. Lacher, Die Neue Seidenstraße - Geopolitik und Macht, Südwestdeutscher Verlag für Hochschulschriften, Saarbrücken, 2016.

${ }^{232} \mathrm{Vgl}$. Europäische Kommission (Hrsg.), Weißbuch „Fahrplan zu einem einheitlichen europäischen Verkehrsraum - Hin zu einem wettbewerbsorientierten und ressourcenschonenden Verkehrssystem“, KOM (2011) 144 endgültig vom 28.03.2011, S. 18 (3.4. Die externe Dimension).
} 
wichtigsten Wirtschaftspartnern auf globaler Ebene umfassende internationale Abkommen über Luftverkehrsdienste geschlossen und Beschränkungen für Investitionen in den Luftverkehr in Drittländern beseitigt werden. ${ }^{233}$

Von erheblicher Bedeutung für die Zukunft wird das Engagement der EU im Satellitensektor sein, wo Europa in der Vergangenheit nie so aktiv war wie die Vereinigten Staaten, Russland oder China. Fakt ist jedoch, dass die Entwicklung und Errichtung des europäischen globalen Navigationssatellitensystems Galileo sowie des europäischen geostationären Navigations-Ergänzungsdienstes Egnos den Verkehrssektor in Europa erheblich unterstützt. Man denke nur an die Navigationssysteme, die heute nicht nur in Autos vorhanden sind, sondern für die Flug- oder Seefahrtsnavigation auf schwierigen Strecken unverzichtbar sind.

Zudem wird sich die Union auch entschieden mit der Revolution des Verkehrs hinsichtlich aufkommender Technologien ${ }^{234}$ auseinandersetzen müssen, sodass eine intelligentere, umweltfreundlichere und effizientere Mobilität von Personen und Gütern weltweit möglich wird (smart mobility). ${ }^{235} \mathrm{Zu}$ derartigen Trends im Verkehrssektor gehören Automatisierung, Digitalisierung und gemeinsam genutzte Mobilitätsdienste. Die Union wird ihr Engagement für diese Technologien verstärken müssen, da sie den Verkehrssektor effizienter gestalten, die Verkehrssicherheit verbessern, die Umweltbelastung reduzieren und die Verkehrsüberlastung verringern muss. ${ }^{236}$

\footnotetext{
${ }^{233} \mathrm{Vgl}$. ebenda.

${ }^{234}$ Von besonderer Bedeutung sind auch intelligente Verkehrsmanagementsysteme (ITS), die Informations- und Kommunikationstechnologien auf den Straßenverkehrssektor, einschließlich Infrastruktur, Fahrzeuge und Nutzer, sowie auf das Mobilitäts- und Verkehrsmanagement und für Schnittstellen mit anderen Verkehrsträgern anwenden: (1) ERTMS = Europäisches Eisenbahnverkehrsleitsystem, das die zahlreichen nationalen Zugsteuerungs- und -führungssysteme durch eine einzige Struktur ersetzen soll; (2) SESAR = Forschungsprojekt zum Flugverkehrsmanagement (ATM) im gemeinsamen europäischen Luftraum, das die Verbesserung der Leistung des Flugverkehrsmanagements (ATM) durch die Modernisierung und Harmonisierung der ATM-Systeme durch die Festlegung, Entwicklung, Validierung und Anwendung innovativer technologischer und betrieblicher ATM-Lösungen zum Ziel hat; (3) RIS = River Information Systems, die entwickelt wurden, um die schnelle Übertragung elektronischer Daten zwischen Schiffen und Bodenbetreibern durch den Austausch von Echtzeit- und vorausschauenden Informationen zu ermöglichen; (4) VTMIS = Vessel Traffic Management Information System, das auf die Verbesserung der Sicherheit und die Minimierung der Umweltschäden bei Schiffsunfällen abzielt; siehe dazu Europäischer Rechnungshof (Hrsg.), Hin zu einem optimierten Verkehrssektor in der EU: Welche Herausforderungen gilt es zu bewältigen?, Landscape-Analyse, Luxemburg, 2018, S. 22.

${ }^{235} \mathrm{Vgl}$. Ch. Perathoner, in diesem Band.

${ }^{236} \mathrm{Vgl}$. Europäischer Rechnungshof (Hrsg.), Hin zu einem optimierten Verkehrssektor in der EU: Welche Herausforderungen gilt es zu bewältigen?, Landscape-Analyse, Luxemburg, 2018, S. 23.
} 
Open Access Dieses Kapitel wird unter der Creative Commons Namensnennung 4.0 International Lizenz (http://creativecommons.org/licenses/by/4.0/deed.de) veröffentlicht, welche die Nutzung, Vervielfältigung, Bearbeitung, Verbreitung und Wiedergabe in jeglichem Medium und Format erlaubt, sofern Sie den/die ursprünglichen Autor(en) und die Quelle ordnungsgemäß nennen, einen Link zur Creative Commons Lizenz beifügen und angeben, ob Änderungen vorgenommen wurden.

Die in diesem Kapitel enthaltenen Bilder und sonstiges Drittmaterial unterliegen ebenfalls der genannten Creative Commons Lizenz, sofern sich aus der Abbildungslegende nichts anderes ergibt. Sofern das betreffende Material nicht unter der genannten Creative Commons Lizenz steht und die betreffende Handlung nicht nach gesetzlichen Vorschriften erlaubt ist, ist für die oben aufgeführten Weiterverwendungen des Materials die Einwilligung des jeweiligen Rechteinhabers einzuholen.

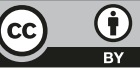

